\title{
Reflexiones sobre cronotipologías en Arqueología de la Arquitectura. Métodos y sistemas de análisis
}

\section{Thoughts on chronotypologies within Archaeology of Architecture. Methods and systems of analysis}

\author{
Cristina Vargas Lorenzo \\ Trífora S.C. Arqueología y Restauración de Edificios \\ e-mail: trifora.sc@gmail.com
}

\section{RESUMEN}

Ofrecemos una reflexión sobre el estado de la cuestión de los métodos y sistemas que rigen los estudios tipológicos desde sus orígenes italianos hasta su llegada a la Península Ibérica en el contexto de Proyectos de Investigación, tesis y estudios específicos. Asimismo, presentamos el esquema de trabajo que venimos desarrollando aún de manera experimental en los recintos del Alcázar de Sevilla, cuyo objetivo es generar unas claves que sirvan para la caracterización, definición y determinación de técnicas constructivas a escala local.

Palabras clave: Estratigrafía; tipología; metrología; tipología constructiva; Alcázar de Sevilla.

\begin{abstract}
This paper reflects on the state of the art of those methods and systems which rule the typological studies, from its Italian origins until its arrival in the Iberian Peninsula, thanks to the development of research projects, thesis and specific studies. The working scheme applied experimentally to analyse the areas of the Alcazar of Seville is besides here explained, with the aim of generating codes to characterise, define and determine the local building techniques.
\end{abstract}

Keywords: Stratigraphy; typology; metrology; building typology; Alcazar of Seville.

Recibido: 26 junio 2012. Aceptado: 21 marzo 2013.

Cómo citar este artículo / Citation

Vargas Lorenzo, C. 2013: "Reflexiones sobre cronotipologías en Arqueología de la Arquitectura", Arqueología de la Arquitectura, 10 : e001. doi: http://dx.doi.org/10.3989/arq.arqt. 2013.001

\section{Copyright}

(c) 2013 CSIC. Este es un artículo de acceso abierto distribuido bajo los términos de la licencia Creative Commons Attribution-Non Commercial (by-nc) Spain 3.0. 


\section{FUNDAMENTO}

Los estudios tipológicos han sido objeto en los últimos años de una revisión conceptual cuyo resultado ha sido la transformación de sus principios metodológicos así como su posterior incorporación a la órbita de lo elevado, trascendiendo el conocimiento que podía obtenerse de ellos hasta hace relativamente poco tiempo.

En este sentido, si nos retrotraemos al pasado, los primeros intentos de los que tenemos constancia a la hora de llevar a cabo una sistematización de fábricas y aparejos los encontramos en trabajos como los de Lugli (1957) y Adam (1996) para tipologías romanas, las aportaciones de Pavón (1999), cuyo esfuerzo de documentación y recopilación sobre técnicas constructivas históricas es inestimable, o Jiménez Martín (1989), con el estudio métrico de las fábricas antiguas en la Puerta de Sevilla en Carmona, enfocándolo desde la tradicional Arqueología de la Construcción. No obstante, y sin menospreciar la calidad de los trabajos anteriores, la naturaleza de los estudios tipológicos que vamos a tratar en este texto son los que se encuadran dentro de la disciplina arqueológica. Dicha tipología se fundamenta sobre principios bien distintos, haciendo notar que los análisis visuales tradicionales no pueden ser más que unos estudios previos a la investigación ulterior. Es decir, siguiendo las premisas de Caballero (2009), "tipo" y "estrato" son dos conceptos complementarios entre sí, estando la tipología preceptivamente asociada a la estratigrafía, ya que son las relaciones contextuales las que posibilitan la asignación de valores cronológicos a los objetos, ya sean sometidos a la estratigrafía o a la tipología. Ambos conceptos son susceptibles de ser complementados con un aparato documental y analítico que en conjunto hagan comprensibles los procesos diacrónicos que sufre el edificio. El método resulta fundamental en el proceso de caracterización, siendo necesario en primer lugar una ordenación de los objetos tipificables insertos en los estratos a través de la estratigrafía, asignándoles una cronología, para en un segundo lugar proceder a su clasificación. Realizadas estas consideraciones generales, pretendemos hacer una reflexión sobre los estudios tipológicos con el objeto de ilustrar cuáles son a día de hoy sus necesidades y carencias, si es que las hubiera, teniendo presente que es el afán de reciclaje y perfeccionamiento el motor que impulsa a toda disciplina a superarse de cara a estudios futuros.

\section{LA TIPOLOGÍA. SUS INICIOS}

La eficacia de los estudios tipológicos ha sido una cuestión discutida desde el surgimiento de la Arqueología de la Arquitectura como disciplina; de hecho, en la actualidad sigue costando admitir en ciertos foros la idea de que los arqueólogos hayan asumido esta labor realizada anteriormente desde otras áreas de conocimiento, siendo diferentes los métodos de los que cada una se sirve para acometer sus investigaciones. La Arqueología de la Arquitectura, más que una herramienta de análisis, es un corpus de información que hace que todos los elementos que se integran en él tengan un significado, no como entes independientes, sino como un todo en el que cada parte está ligada a las demás de tal forma que si las separásemos no tendrían significado alguno y por lo tanto carecerían de valor. La "disección” de este "todo" tan sólo es una manera de optimizar la información buscando que sea comprensible, formando los estudios cronotipológicos parte de este sistema. En este sentido, siendo conscientes de la diversidad y complejidad conceptual que la tipología posee en según qué disciplinas, creemos conveniente hacer una breve digresión al respecto, ya que uno de los objetivos de nuestra reflexión es matizar la idea de que las tipologías en Arqueología de la Arquitectura guardan relación directa con la Teoría de los Estilos. No pretendemos decir con esto que los investigadores que se acercan a la realidad del patrimonio construido desde la perspectiva artística hagan mal uso de sus herramientas; sin embargo, al responder a aspectos únicamente formales y estéticos carecen de la precisión suficiente como para contextualizar el documento material, aislándolo de su realidad histórica, y por ende, cronológica.

Podemos citar como ejemplos el atribucionismo y el formalismo ${ }^{1}$, métodos que tienen como base el análisis formal al que se le une la consulta de las fuentes documentales en combinación con apreciaciones de carácter social. Estas cuestiones quedan reflejadas en algunos estudios estilístico-formales ${ }^{2}$, siendo la cronología la que brilla por su ambigüedad. Otra carencia que observamos es la etereidad con la que se trata la

\footnotetext{
1 Atribucionismo o "estilo", donde se atribuye a cada objeto un estilo predeterminado. Formalismo: se estudia la obra de arte como un ente independiente, no teniendo en cuenta su contexto.

2 No ponemos en duda la calidad de estos trabajos pero no obstante resultan carenciales; la utilización de la fuente escrita es la base del discurso, la cual resulta imprescindible pero como una herramienta auxiliar, es el medio, no el fin de la investigación. Las descripciones estéticas son excelentes aunque carecen de contextualización, y no vemos de qué manera se puede describir objetivamente un edificio "desde dentro a fuera" (Cómez, 1996:13) si no es mediante la aplicación de un instrumento más certero que el ojo humano capaz de depurar esas fuentes documentales que a veces, en un afán porque armonicen con la opinión de las grandes autoridades en la materia, son tomadas como verdades absolutas desembocando en erráticas interpretaciones.
} 
investigación, la cual queda patente en las conclusiones tras el esfuerzo de recopilación documental, lectura, observación y descripción que imposibilita trascender más allá del planteamiento de una o varias hipótesis de partida. Si hay algo que diferencia la Historia del Arte de la Arqueología de la Arquitectura es el componente instrumental, metodológico (Arce, 2009: 13). Esto no quiere decir que las herramientas de la Arqueología de la Arquitectura sean definitivas, de hecho, hay ocasiones en las que no queda otra opción que dejar abierta la investigación a la espera de nuevos datos susceptibles de constatar o transformar la hipótesis evolutiva inicial, pero al menos es ambiciosa, agotando las posibilidades de las ciencias remotas y actuales. En este sentido, los tipos no se presentan como un recurso independiente y anecdótico al estudio de un edificio sino como toda una "biografía constructiva" (Arce, 2009: 24) complementaria e irremediablemente conectada al fenómeno constructivo. En definitiva, la Arqueología de la Arquitectura, a diferencia de sus precursores, aplica al edificio una lectura integral de sus paramentos en función de cuatro estrategias (Parenti, 1988) o herramientas: estratigrafía, tipología, fuentes documentales y analíticas, abriéndose en esta última un amplio campo de experimentación que parte desde las tradicionales, como el Carbono 14, a las más novedosas, como la rehidroxilación. Tratamos por tanto de optimizar, conjugar y relacionar la información que pueda extraerse a través del empleo de cada una de estas herramientas, no perdiendo de vista la disciplina matriz, que no es otra que la Arqueología de la Arquitectura.

\section{LA "TIPOLOGÍA" O "CRONOTIPOLOGÍA" EN ARQUEOLOGÍA DE LA ARQUITECTURA. ANTECEDENTES Y ESTADO DE LA CUESTIÓN}

Para conocer el germen de este tipo de estudios, debemos enfocar nuestra visión hacia Italia, y dentro de este marco geográfico buscar los arqueólogos especializados en el mundo postclásico. De esta manera, y teniendo muy presente la creación en 1970 del ISCUM bajo las directrices de Mannoni (Instituto de historia de la cultura medieval en Génova), comenzaron a surgir los primeros trabajos en los que se fijaron clasificaciones tipológicas relativas a elementos arquitectónicos concretos como vanos de puertas y ventanas (figs. 1, 2, 3). Su estudio fue satisfactorio a escala regional, ya que al ser modelos por lo general muy repetitivos y estar dotados en la mayoría de los casos de un epígrafe que indicaba la apertura de esa puerta o ventana, se convirtieron en elementos axiomáticos. Muestra

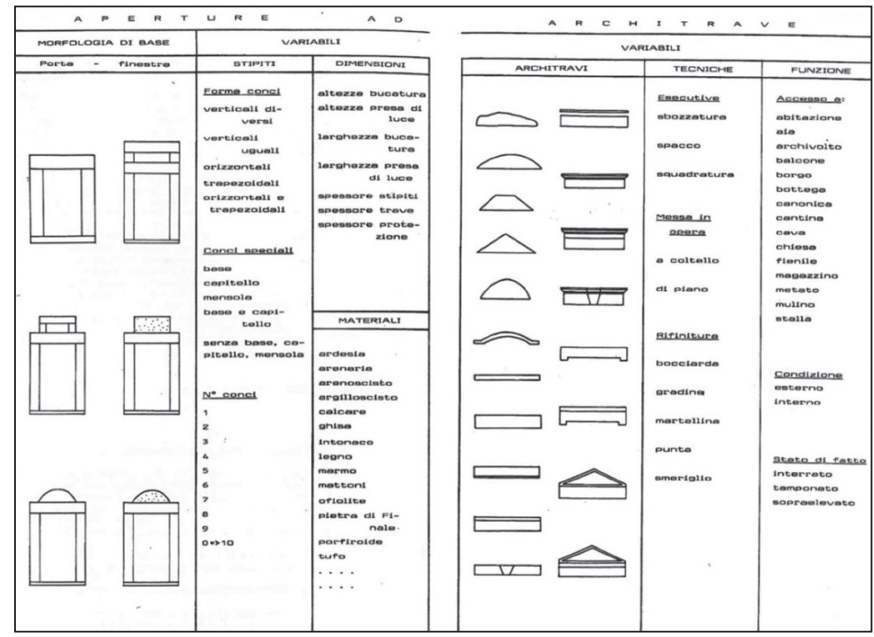

Figura 1. Tablas tipológicas de vanos y arquitrabes (Ferrando, Mannoni y Pagella, 1989: 658)
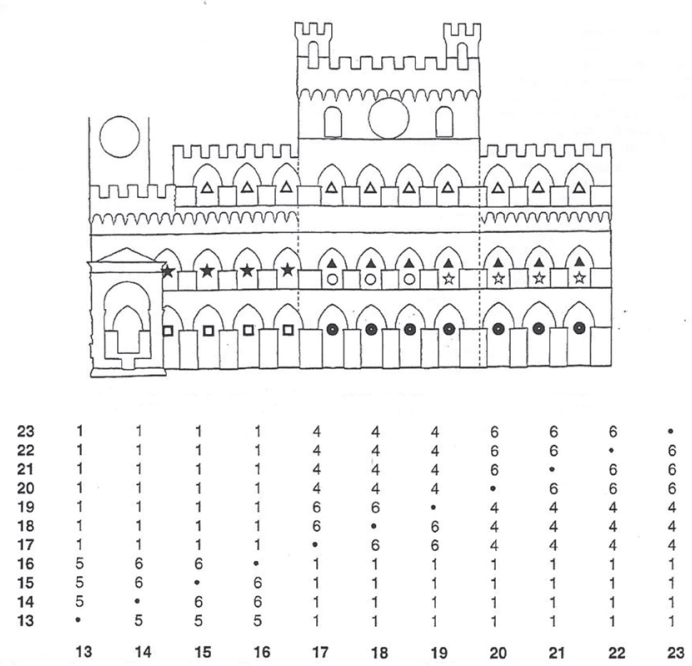

Figura 2. Variables cronotipológicas de vanos de la fachada del Palacio público de Siena (Gabrielli, 1996: 34)

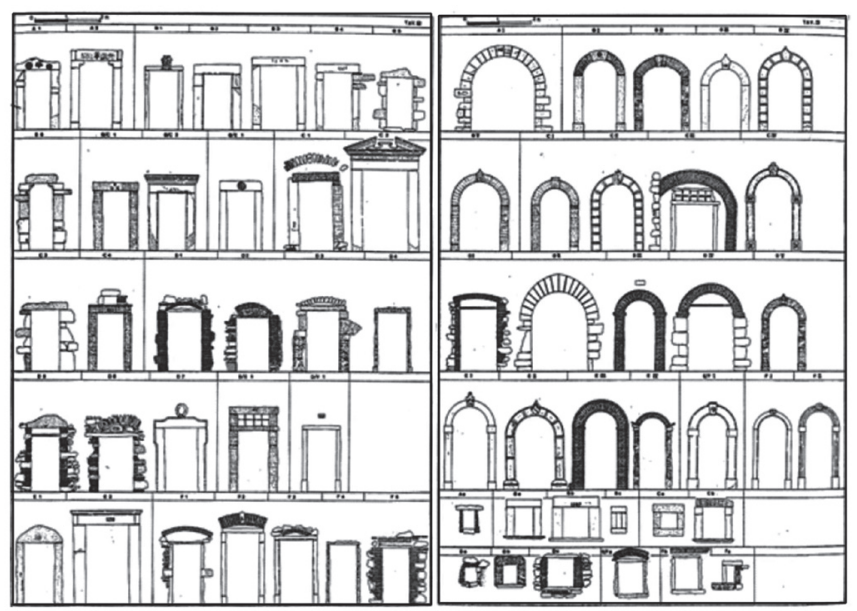

Figura 3. Cronotipologías de vanos (Quirós, 1992: 733) 
de ello son los trabajos realizados por Mannoni, Gabrielli o Quirós (Mannoni, 1976; Ferrando, Mannoni y Pagella, 1989; Gabrielli, 1996; Quirós, 1992), pudiendo establecer cronologías fiables para determinados elementos de una secuencia estratigráfica relativa gracias a sus características tipológicas (Sánchez, 2007: 75).

El siguiente avance consistió en la ampliación del campo de estudio a los aparejos murarios, proponiéndose clasificaciones tipológicas de los mismos. De nuevo será Italia la pionera; no obstante en este punto debemos hacer una aclaración, ya que hay que tener en cuenta la notable heterogeneidad que caracteriza las distintas escuelas que operan en el ámbito de la "Arqueología de la Arquitectura" (Quirós, 2005a:7), pues la diversidad de ambientes geográficos en los que estas investigaciones se desarrollan hace que se aborden de manera bien distinta, predominando en algunas ocasiones y como veremos a continuación, una línea más encaminada al estudio de sistemas productivos, en otras a aspectos constructivos, etc., siendo esencial la problemática de cada edificio en concreto.

Así pues, Mannoni (1994a), en sus trabajos desarrollados desde el ISCUM centrados en las cronotipologías edilicias de la Liguria centro-oriental, propone una clasificación de la "familia" de técnicas constructivas más importantes sobre la base de los aspectos constructivos y funcionales más allá de los formales, defendiendo los estudios cronotipológicos como un método de datación absoluta a escala regional, de fácil uso, bajo coste, y con una aproximación no inferior a la que pueda ofrecer cualquier método científico (Mannoni, 1997). Para ello elabora una metodología que pasa por la consideración del "artefacto" a estudiar como el resultado de una serie de condicionantes (técnicos, estilísticos, destino social, uso, función) que hacen que dicho elemento tenga una consideración concreta dentro del proceso productivo humano.

Su labor por tanto es valiosa en cuanto a interés por la extracción de conclusiones cronológicas en la línea de análisis tipológico y de mensiodatación ${ }^{3}$, pero será Parenti (1983) el que, tomando de Mannoni y Fossati las premisas en cuanto a indicadores cronológicos se refiere, haga una primera clasificación que será importada en España (Tabales, 1997), pues algunas de las tipologías recogidas en sus tablas podrán ser extrapoladas a nuestro marco geográfico. En este sentido, partiendo de la posibilidad de aplicar el método estratigráfico a la lectura de

\footnotetext{
${ }^{3}$ Interesa destacar la labor de Mannoni en la datación de ladrillos en Italia (Mannoni, 1994b), Jiménez Hernández para el caso español (Jiménez Hernández, 2009), o Quirós en ambos (Quirós, 1996).
}
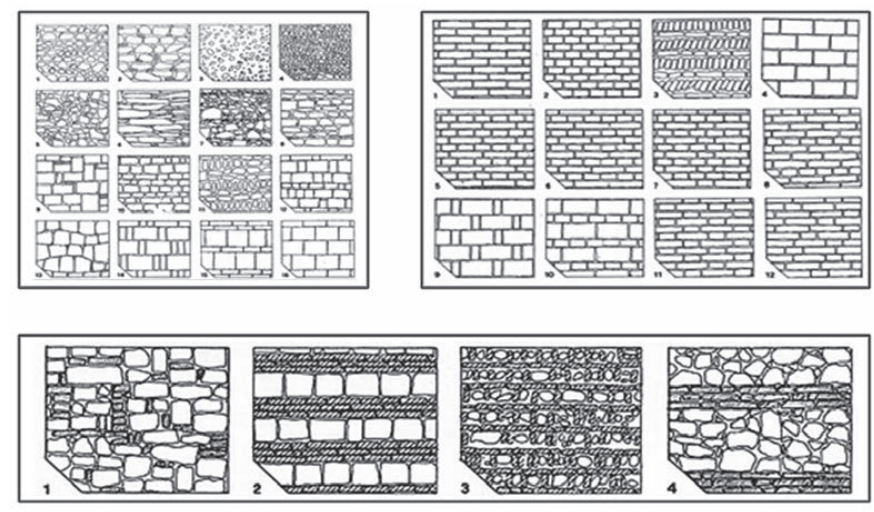

\begin{tabular}{|c|c|}
\hline & TECNICA COSTRUTTIVA \\
\hline Materiali & 0123456789 \\
\hline Laviorazione & 0123456789 \\
\hline Apparecchiatura & 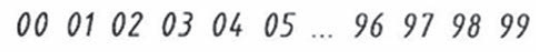 \\
\hline Finitura & 0123456789 \\
\hline Malta & 0123456789 \\
\hline
\end{tabular}

Figura 4. Tablas tipológicas de aparejos pétreos, mixtos y de ladrillos en función de sus técnicas constructivas (Parenti, 1983: 335)

paramentos, organizará unas clasificaciones de aparejos murarios en función de los materiales constructivos a pesar de su heterogeneidad (fig. 4). Su propuesta también contempla otras cuestiones indispensables como el grado de tratamiento realizado sobre el material, el análisis pormenorizado de la técnica constructiva, la métrica, así como el estudio de la técnica del acabado del material a través de sus huellas (fundamentalmente de aparejos pétreos), finalizando el proceso con el análisis de materiales aglutinantes, es decir, los morteros y sus componentes. Este sistema de lectura tipológica lo aplicará en Rocca de San Silvestro, sentando las bases para futuras intervenciones en el patrimonio edificado.

En esta línea también podemos incluir posteriores trabajos en el contexto del ISCUM. Sus colaboradores, de la misma manera que sus predecesores, seguirán esta vía emprendida, poniendo en un lugar importante del análisis los contenidos sociales y técnicos que se desprenden de cualquier empresa arquitectónica reformulándolos en términos de la Historia de la Producción (Quirós, 2002: 9). Buenos ejemplos los tenemos en actuaciones realizadas en la región de Liguria (Cagnana, 2005), como el caso del análisis de la arquitectura en piedra de época medieval en Génova, a partir del cual se ha podido profundizar en el mundo de las élites urbanas identificando a los autores 


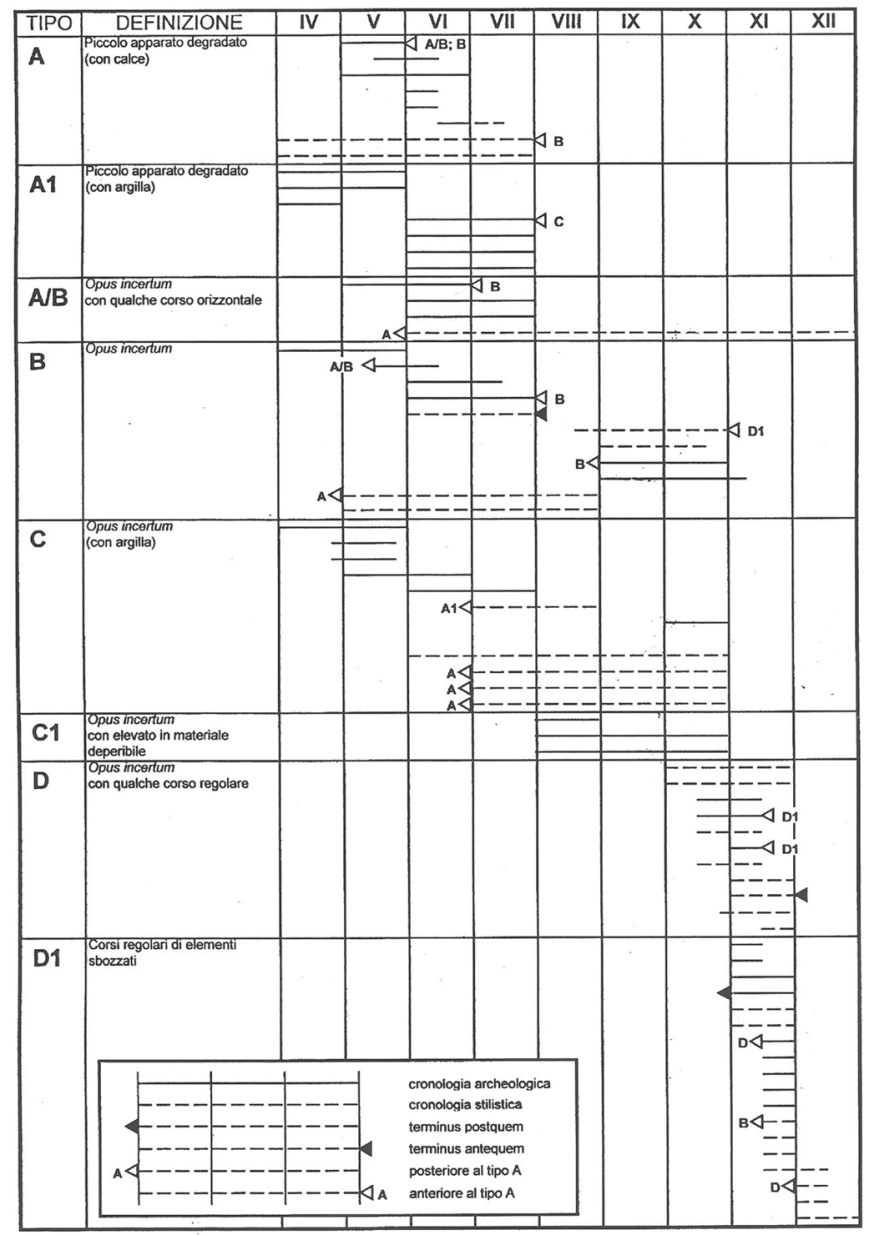

Figura 5. Tabla cronotipológica de las técnicas constructivas documentadas en Liguria entre los siglos V al XI (Cagnana, 2005: 27)

de esas primeras construcciones ${ }^{4}$ (figs. 5 y 6), o también el estudio de las técnicas constructivas asociadas a las estructuras de poder existentes en la Toscana sud-occidental durante los siglos VIII al XIV (Bianchi, 2005). De la misma manera que en el trabajo anterior, el proceso de documentación fue muy útil para apoyar el discurso posterior, centrado en el análisis de las transformaciones que se operan en la manera de construir desde la aparición de los primitivos poblados de los siglos VII-VIII, cuyo material predominante era la madera, pasando por asentamientos ya mucho más estructurados durante los siglos VIII al IX, momento en el que se comenzará a emplear la piedra. Al mismo tiempo harán su aparición los maestros especializados en las construcciones con dicho material hasta llegar a los siglos XI-XII donde la complejidad del trabajo

\footnotetext{
${ }^{4}$ Gracias a la combinación de herramientas de naturaleza científica con fuentes documentales ha podido desentrañar los aspectos sociales de estos "magistri Antelami”, identificándolos como canteros cuya presencia comienza a hacerse patente a partir del s.XII.
}

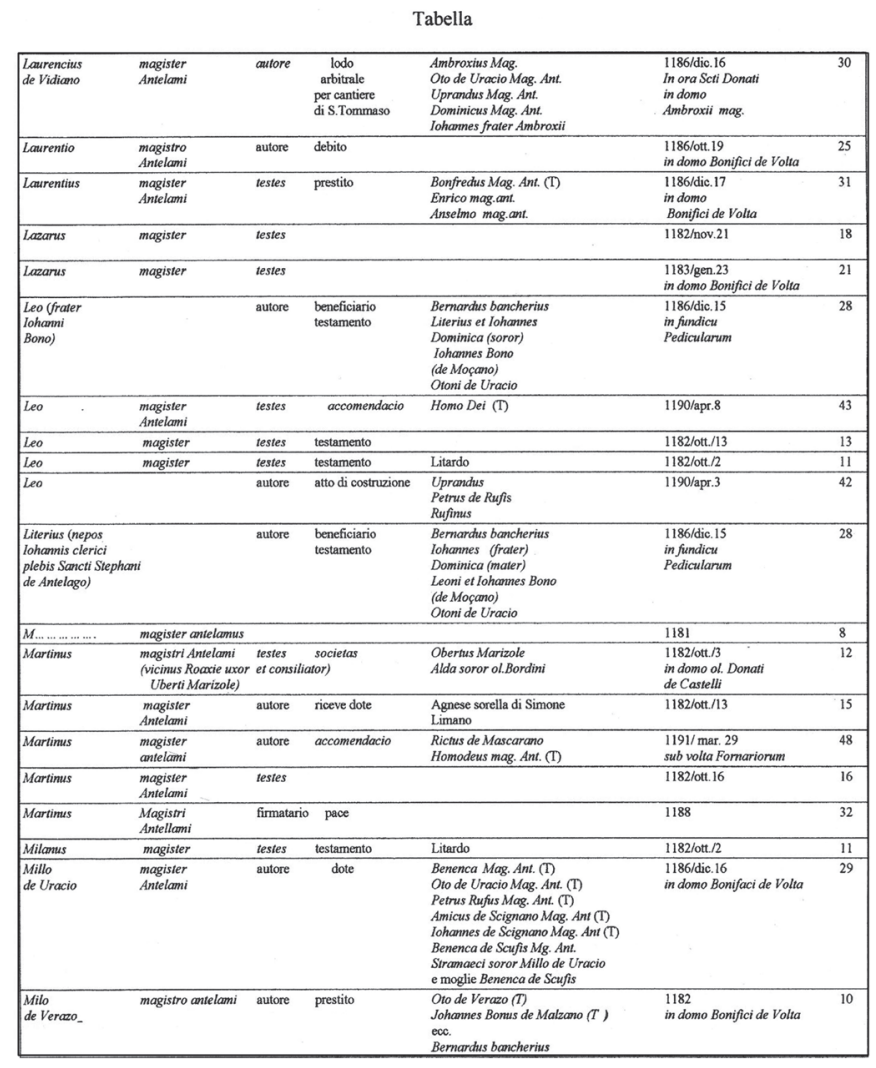

Figura 6. Resultado del proceso de revisión de las fuentes escritas. En el diagrama observamos por orden alfabético algunos nombres de canteros "magistri antelami" mencionados en un documento notarial genovés del siglo XII (Cagnana, 2005: 39)

del cantero se hará patente a través de construcciones de castillos asociadas al nacimiento de los señoríos territoriales, finalizando este horizonte de análisis con unos siglos XIII y XIV caracterizados por un nuevo cambio de técnicas motivado por la formación de nuevos pueblos asentados sobre esos castillos preexistentes (fig. 7).

Asimismo, también resulta obligado destacar el trabajo de Quirós (2005b) relativo a las técnicas constructivas de época altomedieval en la ciudad de Pisa y en la Toscana Noroccidental, empleando de manera metódica las herramientas de la Arqueología de la Arquitectura. Analiza en concreto cuatro construcciones medievales religiosas $^{5}$ a las que aplica el método estratigráfico para, en un segundo paso, contextualizarlas en el ambiente productivo de los siglos $\mathrm{V}$ al $\mathrm{X}$, incidiendo en los materiales utilizados, transformaciones de la estructura organizativa de la producción arquitectónica, evolución de la manera de construir, etc., siendo una de sus grandes aportaciones el análisis de las dimensiones de sus construcciones en el

\footnotetext{
5 San Piero a Grado, San Zeno, Santa Cristina y San Matteo.
} 


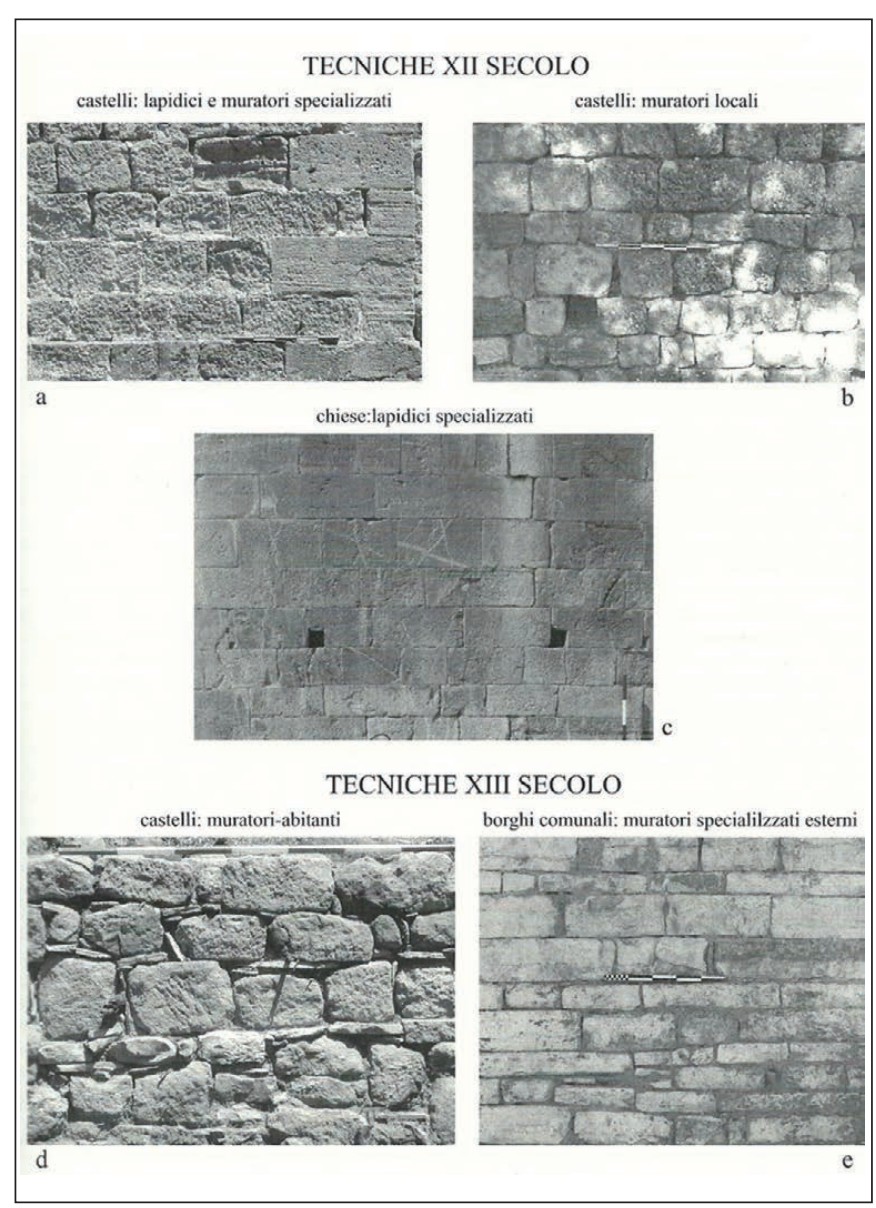

Figura 7. Técnicas constructivas documentadas en los siglos XII y XIII (Bianchi, 2005: 55)

contexto del desarrollo de la escuela arquitectónica local pisana del siglo X (figs. 8 y 9).

En España, comenzarán a importarse a mediados de los años 90, discurriendo por diferentes derroteros epistemológicos, tomando una forma u otra en función de la disciplina a la que se asocie. Podemos hablar de los intentos por parte de la Historia y Arte medieval de crear verdaderos tratados de construcción ${ }^{6}$ (Pavón, 1999. Fig.10), o también la denominada Arqueología de la Construcción, cuyos preceptos metodológicos, a pesar de no someterse estrictamente al lenguaje estratigráfico, resultan valiosos por la labor que han venido realizando a la hora de abordar el análisis de las técnicas constructivas, materiales y protagonistas a lo largo de toda la época clásica (Bendala, 1992; Bendala y Roldán, 1999; Roldán, 1992; Pizzo, 2009; Rodríguez, 2004. Fig. 11).

\footnotetext{
${ }^{6}$ Estos tratados se llevarán a cabo desde los planteamientos previos a la revolución harrisiana, es decir, siguiendo la teoría de los estilos, siendo por tanto buenos trabajos en cuanto recopilación de técnicas constructivas pero discutibles en lo que concierne a cuestiones cronológicas.
}

\begin{tabular}{|c|c|c|c|c|}
\hline Edificio & Conterto & Cronología & Funcáón & Técnica \\
\hline San Piero a Grado 1 & & Romana & Casas & A2 \\
\hline San Piero a Grado 2 & & s. Ny & Iglesia & B2 \\
\hline Piazza Cavalieri & Estructura 96 & VII-VIII & Cabaña & $\mathrm{C}_{2}$ \\
\hline San Piero a Grado 3 & & vir--X & Iglesia & B3? \\
\hline San Zeno 1 & & VIII-IX ? & Iglesia & B1 \\
\hline Piazzza Dante & Estructuras I-II & $\mathrm{EK}-\mathrm{X}$ & Casas & B2 \\
\hline San Zeno 2 & & $\mathrm{x}:$ & Iglesia & B2 \\
\hline Piazza Cavalieri & Estructura 79 & Finales $x$ & Vivienda? & B2 \\
\hline Piazza Dante & Edificio IV & Finales $\mathrm{x}-\mathrm{xI}$ & Casas & B2 \\
\hline San Michele alla Verruca & Periodo VI & Finales $\mathrm{X}-\mathrm{xr}$ & Monasterio & B4 4 \\
\hline Piazza Cavalieri & Casa Torre 2, 61 & Inizi XI & Torre & A3 \\
\hline San Isidoro & & Inizi XI & Iglesia & $\mathrm{A3}, \mathrm{BS}$ \\
\hline San Piero a Grado 4 & & 975.1025 & Iglesia & $A 3, B 5$ \\
\hline San Zeno $3 a$ & & 975.1025 & Iglesia & A3 \\
\hline San Zeno $3 \mathrm{~b}$ & & 975.1026 & Iglesia & A2 \\
\hline Santa Cristina & & a. 1006 & Iglesia & A3, BS \\
\hline San Matteo 1 & & $975-1025$ & Iglesia & $\mathrm{A} 3$ \\
\hline
\end{tabular}

Figura 8. Tabla tipológica en la que se reflejan las técnicas constructivas registradas en Pisa en la Alta Edad Media (Quirós, 2005b: 102)

\begin{tabular}{|c|c|c|c|c|c|c|c|c|c|}
\hline & 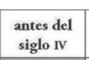 & siglo v & siglov & siglo v v & siglo vir & \begin{tabular}{|c|c|} 
islo vm \\
\end{tabular} & siglo ri & siglox $x$ & siglo x x \\
\hline $\mathrm{A} 2$ & & & & & & & & & \\
\hline A3 & & & & & & & & & \\
\hline B1 & & & & & & & & & \\
\hline B2 & & & & & & & & & \\
\hline B3 & & & & & & & & & \\
\hline B4 & & & & & & & & & \\
\hline BS & & & & & & & & & \\
\hline $\mathrm{C}_{2}$ & & & & & & & & & \\
\hline
\end{tabular}

Figura 9. Tabla cronológica de las técnicas constructivas documentadas en la tabla anterior (Quirós, 2005b: 103)

La Arquitectura también se verá implicada a través de las aportaciones de expertos interesados en el conocimiento de la Historia y de la Arqueología. Es el caso del análisis histórico-arqueológico realizado por Jiménez Martín (1989) en la Puerta de Sevilla en Carmona. Su estudio tipológico hará clasificaciones de piedra, ladri1lo, tapial, fábricas mixtas y elementos varios, en los que hace referencia a la descripción de los materiales, orientaciones, medidas y técnicas constructivas empleadas, todo ello apoyado por un aparato gráfico y fotográfico.

Habrá que esperar a finales de los años 90 y principios del nuevo siglo para ver los primeros resultados de los análisis cronotipológicos relativos a Arqueología de la Arquitectura ${ }^{7}$. En concreto, vamos a destacar dos ámbitos geográficos en los que este tipo de estudios han tenido

\footnotetext{
${ }^{7}$ Antes de la fecha tan sólo podemos destacar algún que otro estudio de ámbito regional, pero que tendrá pocas repercusiones a escala nacional debido a las particularidades tan concretas de los mismos, así como la existencia de ciertas incoherencias en sus planteamientos. Es el caso del estudio de Miyares sobre la identificación de las fases constructivas en el contexto del románico asturiano (Miyares, 1986: 425).
} 


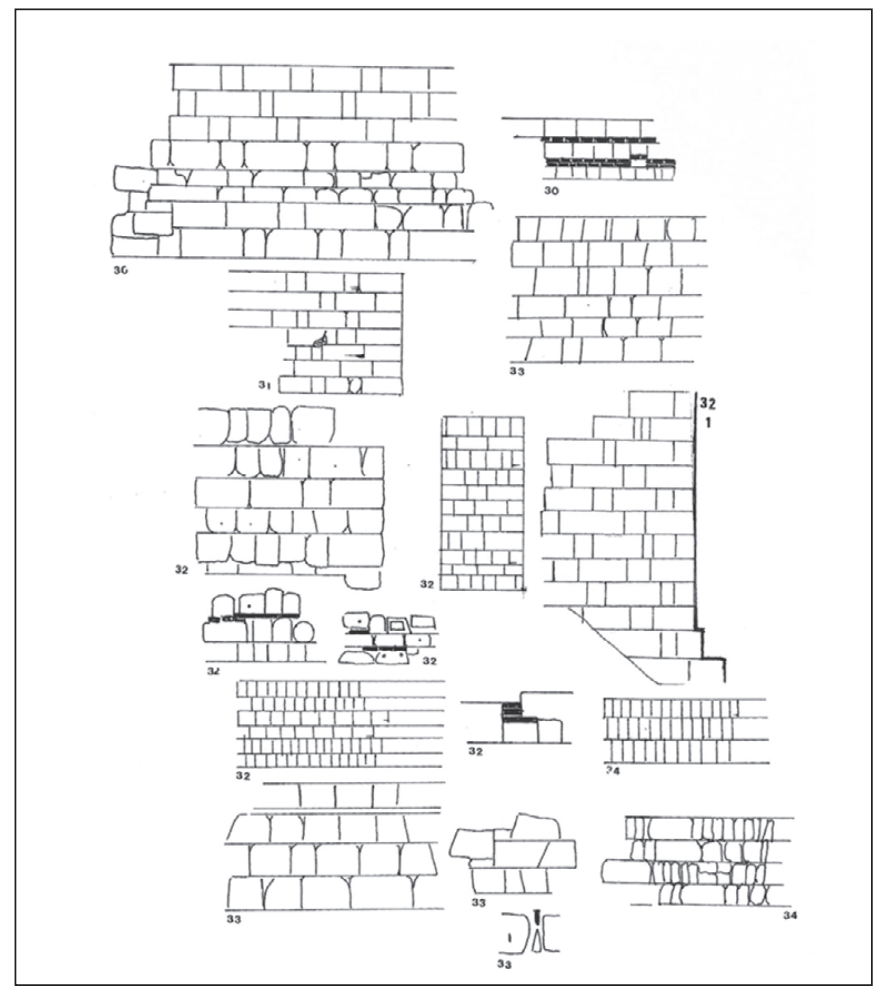

Figura 10. Ejemplo de técnicas constructivas documentadas por Pavón durante el periodo islámico (Pavón, 1999: 583)

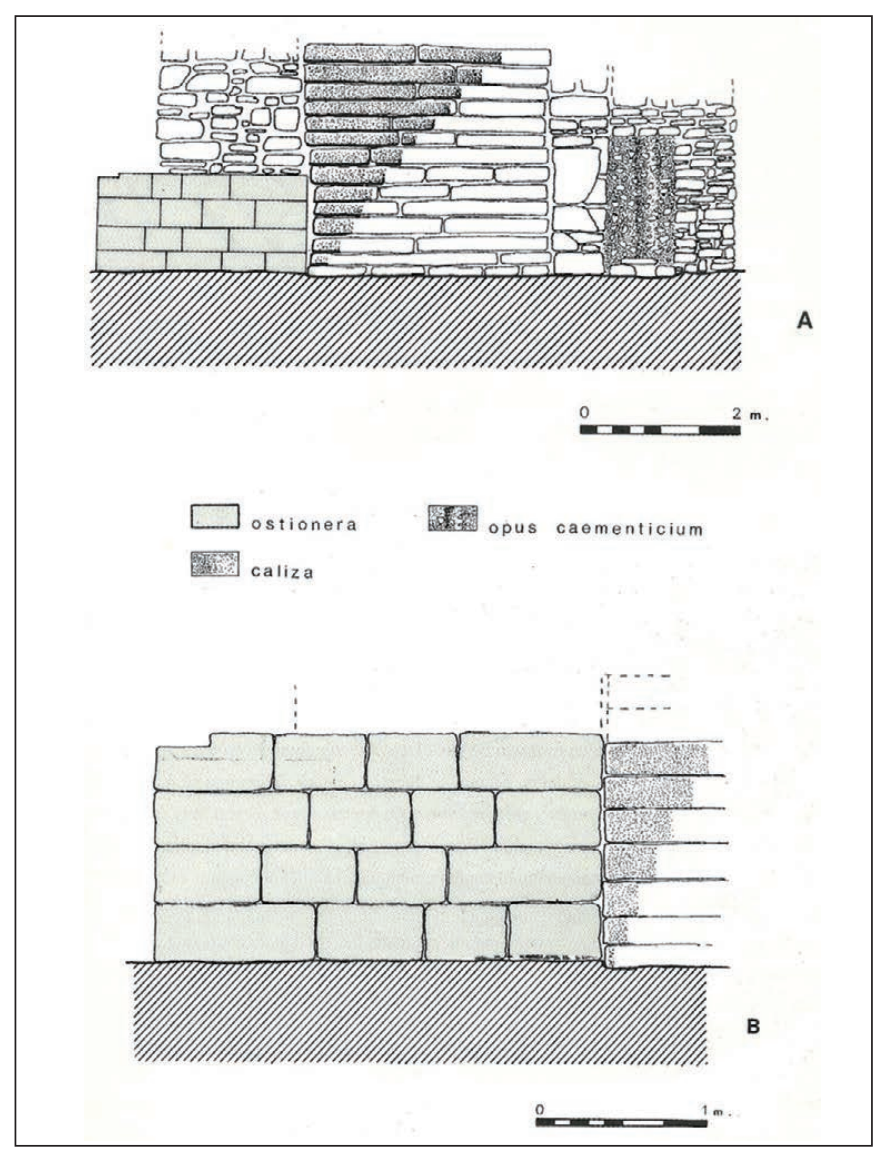

Figura 11. Ejemplo de técnicas constructivas romanas (Roldán, 1992: 57)

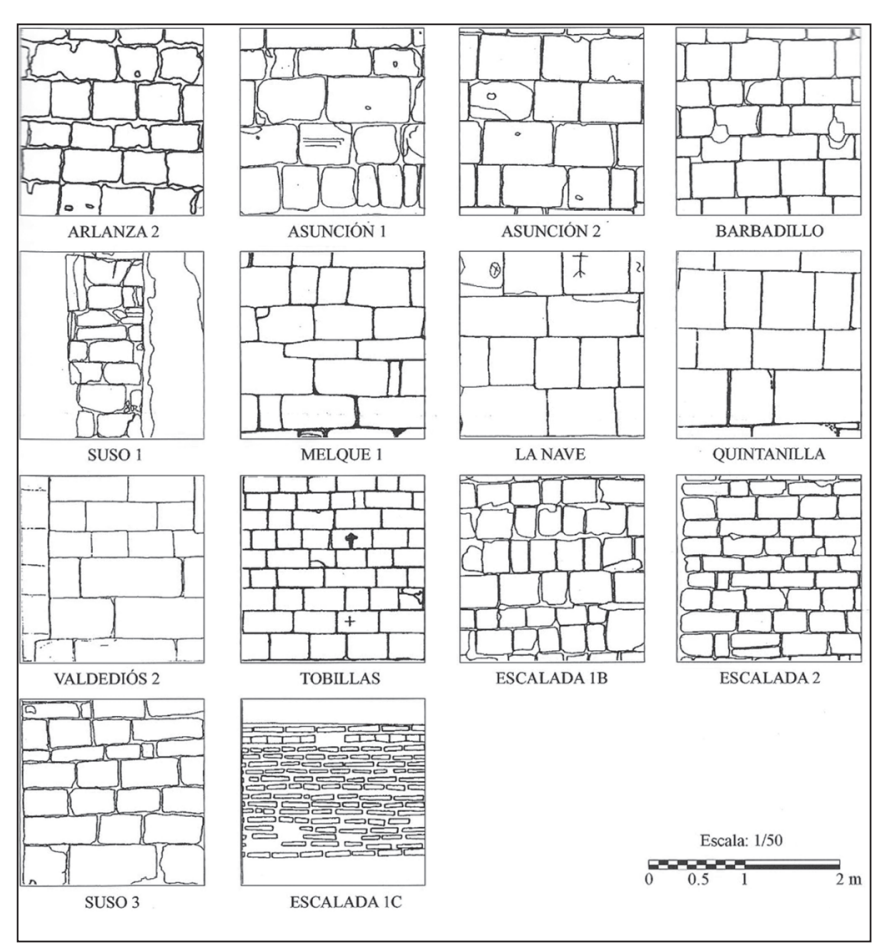

Figura 12. Ejemplo de tipologías constructivas de arquitectura alto medieval documentadas en la Península Ibérica (Caballero y Utrero, 2005: 179)

mayor trascendencia por su profundidad y calidad, como son los llevados a cabo en el País Vasco y en Sevilla. En el primero, es obligado destacar la labor de Caballero, pionero de los estudios paramentales en España'; sus trabajos en torno a las técnicas constructivas altomedievales los abordará bajo una perspectiva íntimamente relacionada con la herramienta estratigráfica, fundiendo las características tipológicas de los aparejos murarios y elementos arquitectónicos con el discurso constructivo, evolutivo y productivo del edificio, dejando patente que el término "técnica constructiva" se emplea frecuentemente como sinónimo de "aparejo" o de "fábrica”, remitiéndose únicamente a la tipología muraria o arquitectónica, cuando en realidad hace referencia a un ciclo productivo con una serie de actividades organizadas y una finalidad concreta que comienza en la cantera y termina en la ejecución del edificio (Caballero, 2009:171. Fig.12).

Otro caso de estudio es el desempeñado en la Catedral de Santa María de Vitoria-Gasteiz (Azkarate, 2001a). Su sistema de lectura cronotipológica se fundamenta en la identificación de una serie de variables que concentra en grupos o “clusters” de carácter técnico y formal llevada

${ }^{8}$ Por citar algunos de sus trabajos: (Caballero y Latorre, 1980; Caballero, 1995; Caballero y Arce, 1997; Caballero, 2000). 


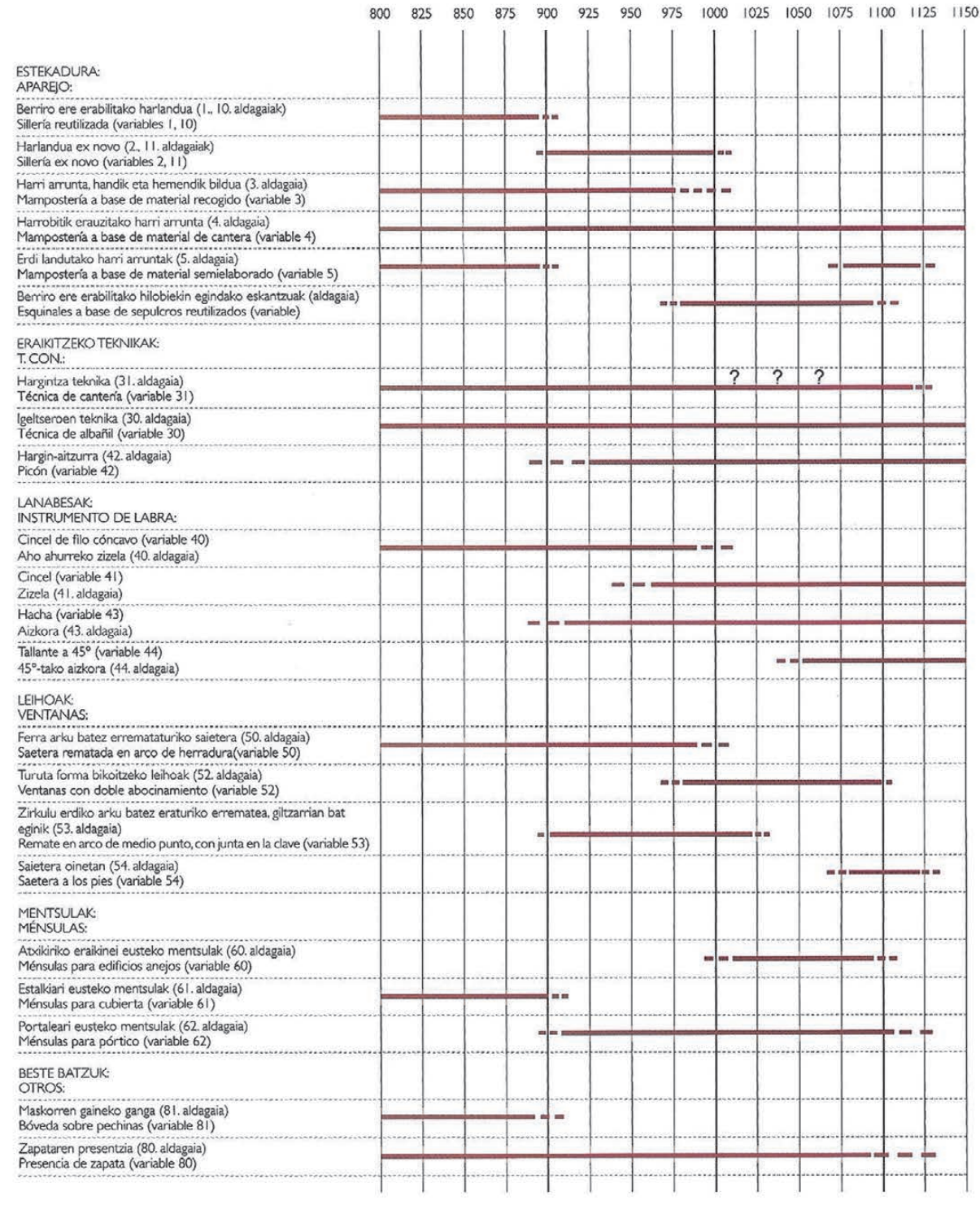

Figura 13. Tabla cronotipológica de las variables seleccionadas (Sánchez, 2007: 326)
Figura 14. Tabla cronotipológica de "clusters" (Sánchez, 2007: 324)

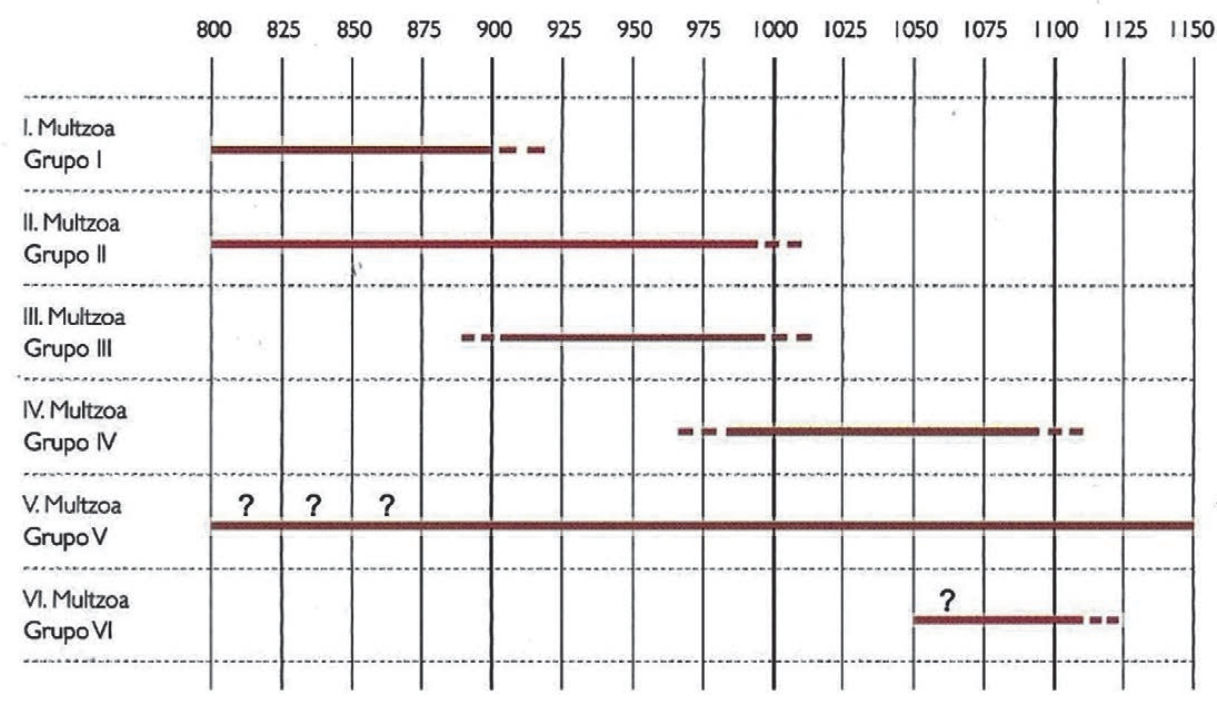


a cabo tras la lectura previa de los principales eventos constructivos (cuyo objetivo es encuadrar cada uno de esos eventos en fases). La práctica de ambos ejercicios de análisis conlleva a la elaboración final de una serie de cuadros en los que se exponen los resultados de manera impecable, ya que por un lado se muestra la tabla analítica de variables y por otro la tabla de edificios con esas variables asociadas por cronologías. En este sentido, estratigrafía, cronotipología y edificio (entendido como el resultado final de un proceso productivo) comparten el mismo peso dentro del discurso teórico, quedando así cubiertos todos los frentes que consideramos preceptivos en el contexto de cualquier estudio de lo elevado. Partiendo del sistema de "clusters" de Azkarate, Sánchez (2007) emprenderá un potente estudio sobre arquitectura altomedieval alavesa, objeto de su tesis ${ }^{9}$. La herramienta estratigráfica le permitirá detectar aquellos edificios con posibles restos prerrománicos, siendo el paso siguiente analizar las variables de los estratos diferenciados, agrupando éstos en conjuntos o "clusters". Finalmente los resultados se volcarán en tablas cronotipológicas apoyadas en razonamientos arqueológicos, históricos, documentales o arqueométricos ${ }^{10}$ (figs. 13 y 14).

La aportación de Quirós y Fernández resulta igualmente providencial, pues aborda el análisis cronotipológico incidiendo en los aspectos sociales y económicos de la producción arquitectónica. Ejemplo de ello es la investigación de la evolución de las técnicas constructivas en Asturias en la Edad Media (2001), donde toma una muestra de varias construcciones de carácter casi exclusivamente religioso datadas a través de la documentación material (epígrafes), fuentes documentales y excavaciones arqueológicas. Los criterios (o variables) que selecciona para analizar las técnicas constructivas son, a saber, tipo de material, elaboración, dimensiones, aparejo, instrumentos para su fabricación y acabado final. Los resultados no sólo se ceñirán a establecer indicadores cronológicos, si no que mostrarán un fiel reflejo de la construcción religiosa asturiana en época medieval desde todas sus vertientes (evolución y transformaciones en función de los aspectos socioeconómicos, ciclo productivo de la piedra, ciclo del ladrillo, problemáticas

\footnotetext{
9 Se centra en la aplicación de nuevas herramientas de análisis basadas en la cronotipología con el objetivo de probar la existencia de iglesias altomedievales, analizarlas y contextualizarlas para, en un segundo momento, ampliar la investigación al conocimiento del poblamiento medieval.

${ }_{10}$ Los intentos de datación no siempre se constatan, pues hay ocasiones en las que las variables no son lo suficientemente numerosas para ser representativas o bien pueden resultar confusas. No obstante, la cronología básica está conseguida desde el primer paso.
}

relacionadas con su producción, etc.). Tampoco podemos olvidar el complejo sistema metodológico que idea Plata $^{11}$ (2008) para el estudio histórico-arqueológico del Valle Salado de Añana. Este caso resulta paradigmático a la hora de valorar la utilidad de la cronotipología, máxime si surgen dificultades en la lectura estratigráfica. En este sentido, el análisis no pudo ejecutarse en su totalidad, por lo que hubo que cambiar la estrategia previa "quizás excesivamente estratigráfica" (Plata, 2003: 243) por otra en la que se enfocaba el conjunto como un proceso productivo fruto de una serie de condicionantes. Dicho cambio supuso invertir el proceso lógico de investigación, es decir, analizar las variables constructivas $^{12}$ en primera instancia para en un segundo momento organizar la secuencia estratigráfica con todas las que pudieran reconocerse en cada una de esas estructuras. Los resultados fueron volcados en un sistema de información geográfica que hizo posible la comprensión del proceso productivo de las salinas en todas sus vertientes. Pero faltaba todavía una cuestión, la de tratar de transformar incertidumbres en certezas. Hasta ahora los datos extraídos habían servido para establecer relaciones de anterioridad-posterioridad, aportando una cronología relativa, pero nada se sabía de las absolutas. Para ello se tomó el recurso de las ciencias auxiliares, analizando por un lado la documentación existente y por otro haciendo estudios arqueométricos. Tenemos aquí pues uno de los ejemplos más interesantes de cómo un análisis en principio, carencial, pudo convertirse a través de la cronotipología en una fuente de información, caracterización y datación asombrosa, dejando patente una cuestión muy importante: la estratigrafía es la base, el fundamento, pero la cronotipología es el complemento, y no un complemento arbitrario sino íntimamente asociada a la estratigrafía, como dos caras de una misma moneda, siendo ambas necesarias y dependientes (fig.15).

Centrándonos ya en el caso sevillano, resulta obligado hablar de la labor de Tabales con su protocolo de lectura paramental ${ }^{13}$. A partir de la experiencia italiana llevará a cabo su propia aportación en base a la casuística local.

\footnotetext{
${ }^{11}$ El estudio arqueológico se llevó a cabo con motivo de la ejecución de un Plan Director elaborado por un equipo multidisciplinar cuyos estudios históricos se encomendaron al Grupo de Investigación en Arqueología de la Arquitectura del País Vasco.

12 En este caso se seleccionaron tres tipos de variables; técnicas (tipo de aparejo, talla, acabado, material empleado), formales (dimensiones, plantas, tipologías de los pozos y almacenes) y espaciales (análisis de ubicación, estudio de las pendientes del terreno).

$13 \mathrm{Su}$ "Sistema de análisis arqueológico de edificios históricos" (Tabales, 1997) ya estaba presente previamente a través de los trabajos realizados.
} 


\section{1- LA CRONOLOGÍA RELATIVA:}

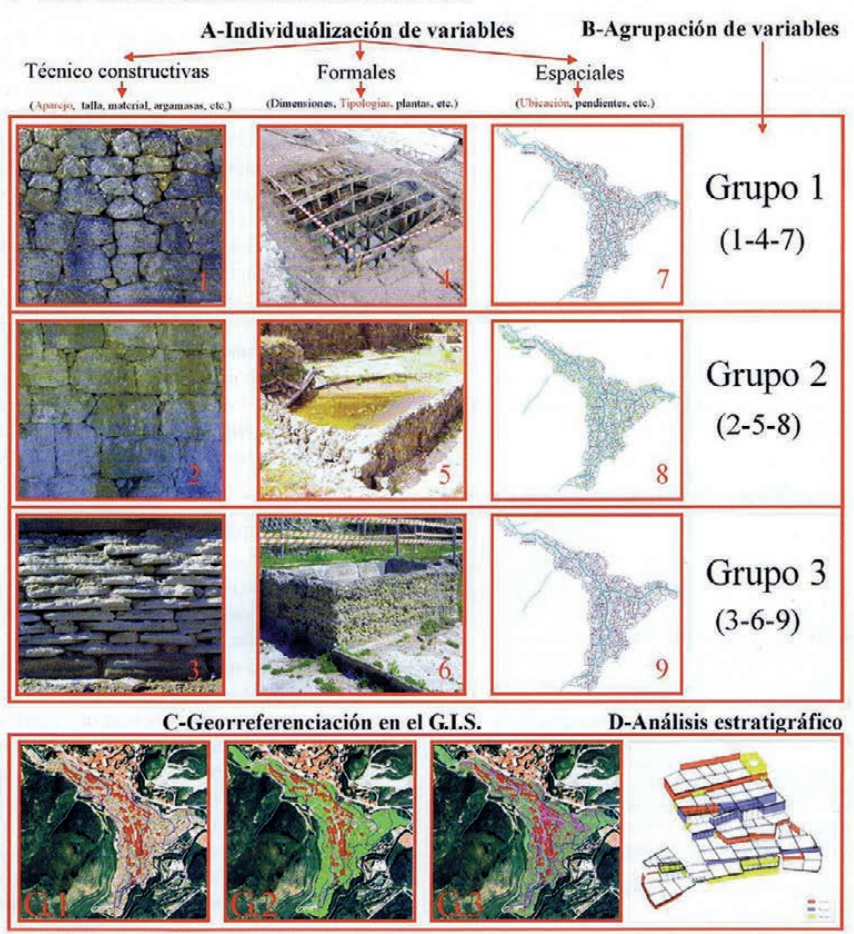

2-LA CRONOLOGÍA ABSOLUTA:

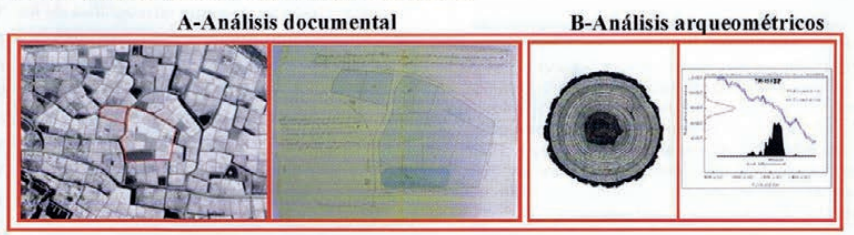

Figura 15. Tabla cronotipológica de las variables seleccionadas (Plata, 2003: 242)

Aplicará su sistema dividido en tres partes (estratigráfico, tipológico, y constructivo ${ }^{14}$, haciendo notar que gran parte de las apreciaciones referentes a las patologías (grietas, combamientos, rupturas estructurales o superficiales, etc.) inciden de manera providencial en la valoración arqueológica general (e incluso estratigráfica. Tabales, 2002a: 196 ${ }^{15}$. Figs. 16-20). Respecto al análisis tipológico, comenzará a aplicarlo en $1990^{16}$ reivindicándolo como parte necesariamente asociada a la estratigrafía. Sus trabajos incluirán un apartado específico reservado al estudio tipológico de aparejos, vanos, forjados, pavimentos y elementos constructivos varios (añadidos, enlucidos, etc.), utilizando

\footnotetext{
$\overline{14}$ Denominado en su tesis "estructural", pero posteriormente el nombre será sustituido por "constructivo" debido a discrepancias con la disciplina arquitectónica, cuyos especialistas consideraban que se incurría en una cierta simplificación del término.

${ }^{15}$ Comenzará a incorporar esta clase de estudios a su sistema en el año 1993 (Tabales, Pozo y Oliva, 2002), consolidándose definitivamente con la Intervención en el Palacio de los marqueses de Marchelina (Tabales, 1995).

${ }^{16}$ Por citar algunos ejemplos: (Tabales, Pozo y Oliva, 2002; Tabales, 2001; Tabales, 2002b).
}

como soporte de diagnóstico una ficha de análisis además de un aparato gráfico en el que de manera simbólica se identifican los diferentes tipos de aparejos detectados.

Para montar las clasificaciones toma el modelo de Parenti, extrapolándolo a nuestro ámbito de actuación y haciendo algunas aportaciones tipológicas más ${ }^{17}$. Su estudio tipológico contará además con una serie de analíticas específicas en las que, al igual que los demás, intentará dar ese salto de lo relativo a lo absoluto a través de análisis arqueométricos, contando para ello con diversos especialistas que contribuirán al conocimiento de la arquitectura islámica andalusí.

De esta forma, desde la puesta en marcha de la aplicación del sistema tipológico en Sevilla a comienzos de los años 90, no se ha parado de investigar sobre esta cuestión, en el empeño de obtener unas tipologías fiables susceptibles de caracterizar y datar el patrimonio arquitectónico de nuestro territorio. Una de las recientes contribuciones ha sido la caracterización cronotipológi$\mathrm{Ca}^{18}$ de las obras de tapial a escala local (Graciani, 2009; Graciani y Tabales, 2008. Fig. 21).

En definitiva, desde la vía iniciada por Mannoni en la década de los 80, la tipología ha sido en los últimos años objeto de trabajos de investigación que han potenciado a la par que justificado su presencia como parte fundamental e imprescindible de cualquier análisis arqueológico de un edificio. No obstante, las recopilaciones y clasificaciones hechas hasta la fecha sobre fábricas concrecionadas, mixtas, técnicas pétreas y ladrillos aún no cuentan con las claves suficientes como para que resulten válidas y extrapolables a otros territorios. Con esto no pretendemos decir en ningún caso que la metodología empleada no sea la idónea o esté obsoleta, sino que falta aún aplicar un "orden" en el contexto del "caos" que supone sistematizar la ingente variedad y diversidad de materiales y técnicas constructivas.

Nuestro objetivo es mejorar el sistema de lectura cronotipológica a través de unas claves que sirvan como referente para caracterizar, definir, contextualizar y determinar cronológicamente técnicas constructivas con unos niveles altos de certeza; también pretendemos que dichas claves resulten válidas y extrapolables tanto dentro del territorio como fuera de él, pero para ello hay que establecer una seriación que pasa por ordenar y codificar cada una de las

\footnotetext{
${ }^{17}$ La clasificación de Parenti la completa con las aportaciones de Clairac y Sáenz, 1877.

18 Previamente en Tabales, 2000.
} 


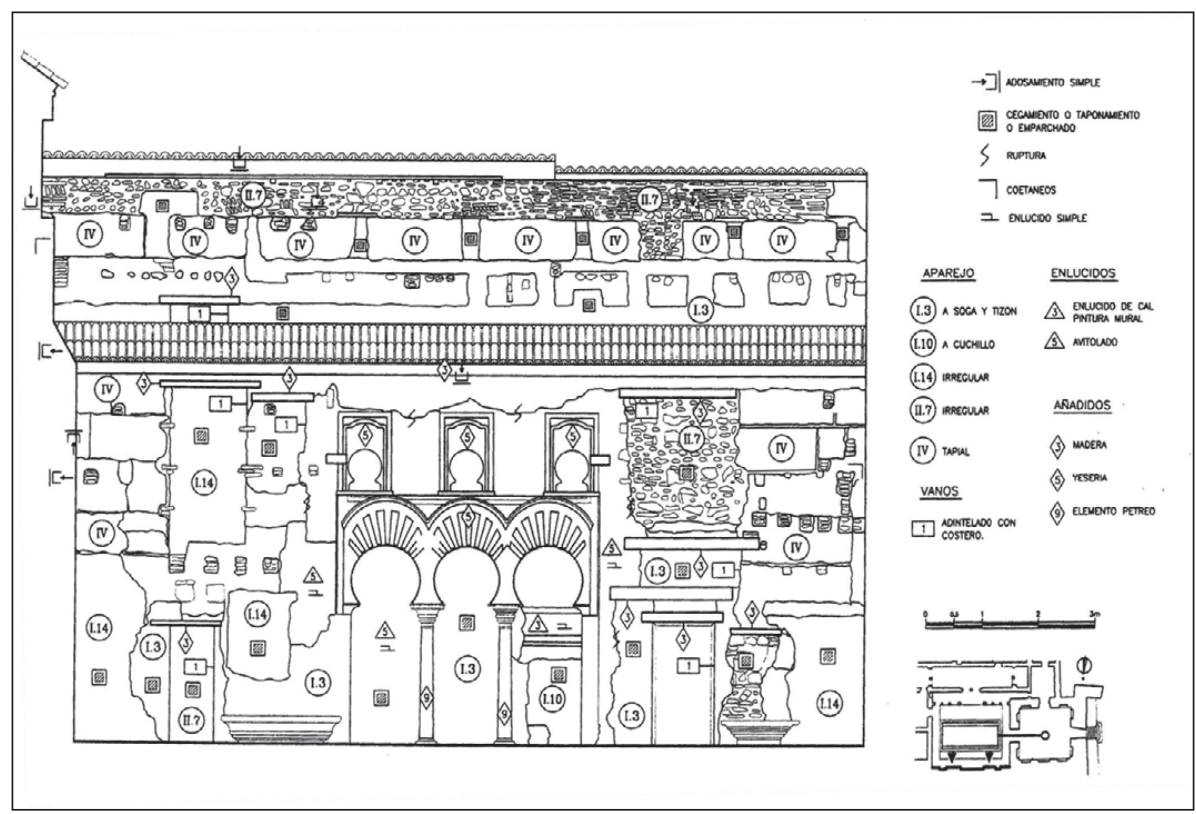

Figura 16. Análisis tipológico y constructivo del Patio del Yeso. Alcázar de Sevilla (Tabales, 2002a: 207)

\section{APAREJO DE LADRILLO \\ Se utilizaró la clasificación de Clairac-1.877 completada con la de Parenti -1988 , numeroda del 1 al 14 - MATR-1.993.}

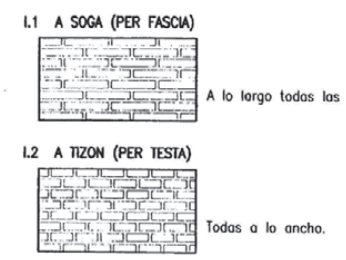

1.3 A SOGA Y TIZON (INGLES, A BLOQUE)

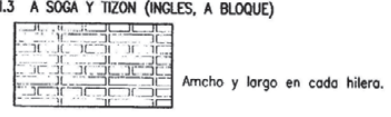

1.4 INGLES ANTIGUO (PERGAROINO)

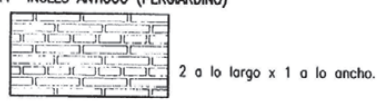

1.5 BELGA (INGLES A CRUZ)

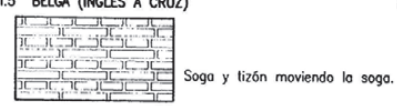

1.6 FAMENCO (GOICO O DATONICO)

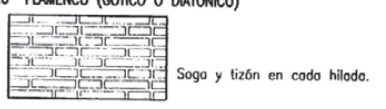

1.7 HOLANDES

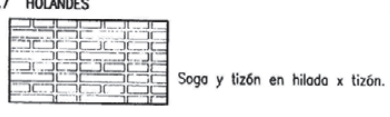

1.8 ESPIGADO

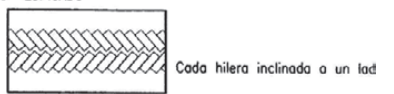

1.9 EMPLECTON

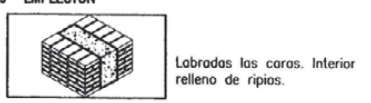

L.10 PER COLTELO (A CUCHILO)

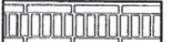

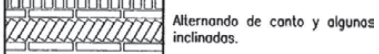

1.11 PER COSTA (IN FOGLO)

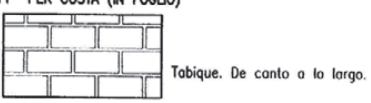

1.12 RAT TAP

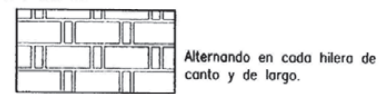

1.13 DENRNE

Alt

L.14 RREGULAR

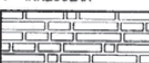

Sin trozodo preconcebido.

Figura 17. Aparejos de ladrillo recogidos por Tabales en su tesis (Tabales, 2002a: 174)

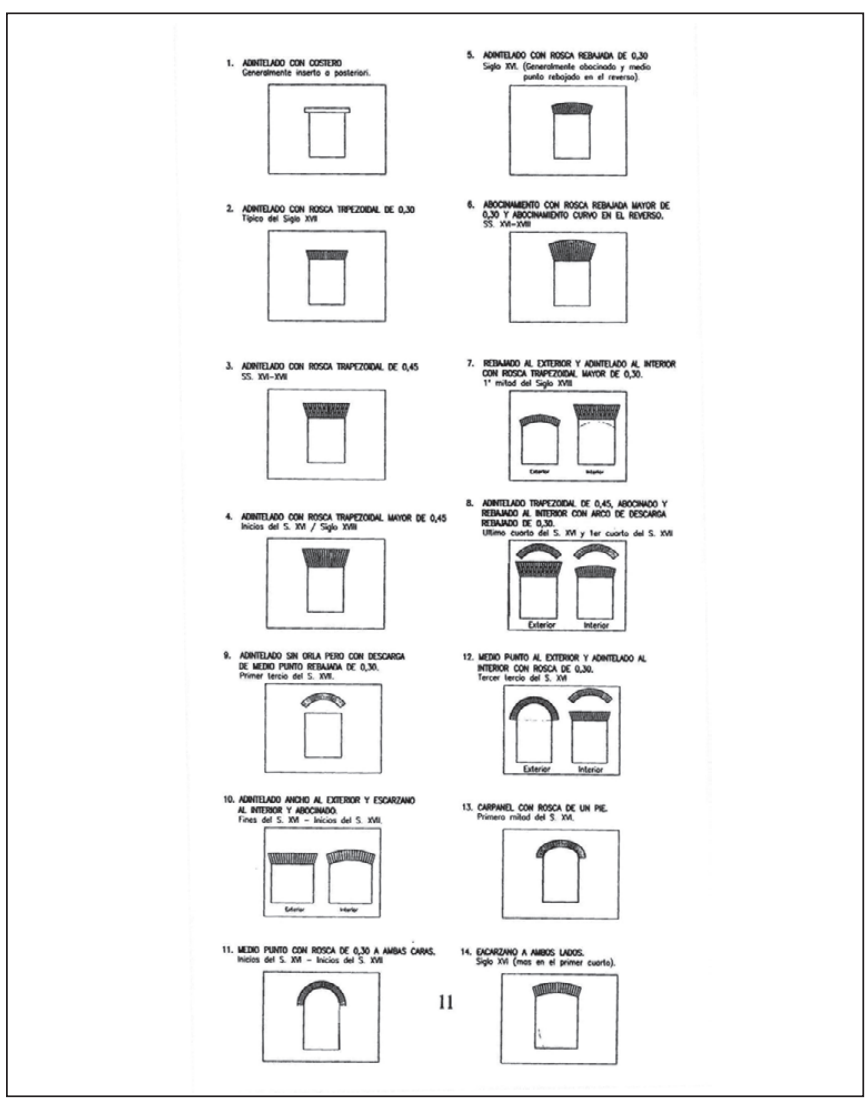

Figura 18. Tabla tipológica de vanos (Tabales, 2002a: 192) 


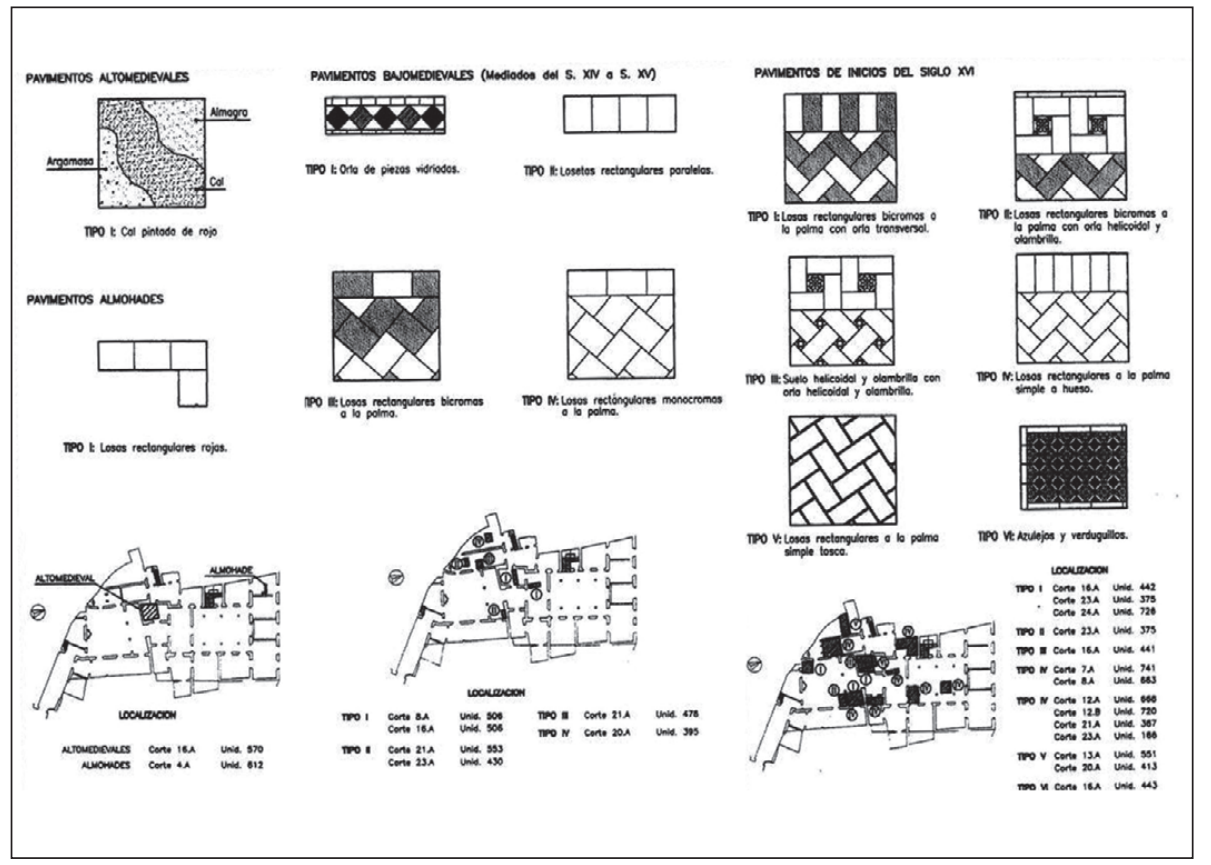

Figura 19. Ejemplo de tipología de pavimentos detectados en la intervención en el Palacio de Conde de Ibarra (Sevilla), en 1995 (Tabales, 2002a: 206)

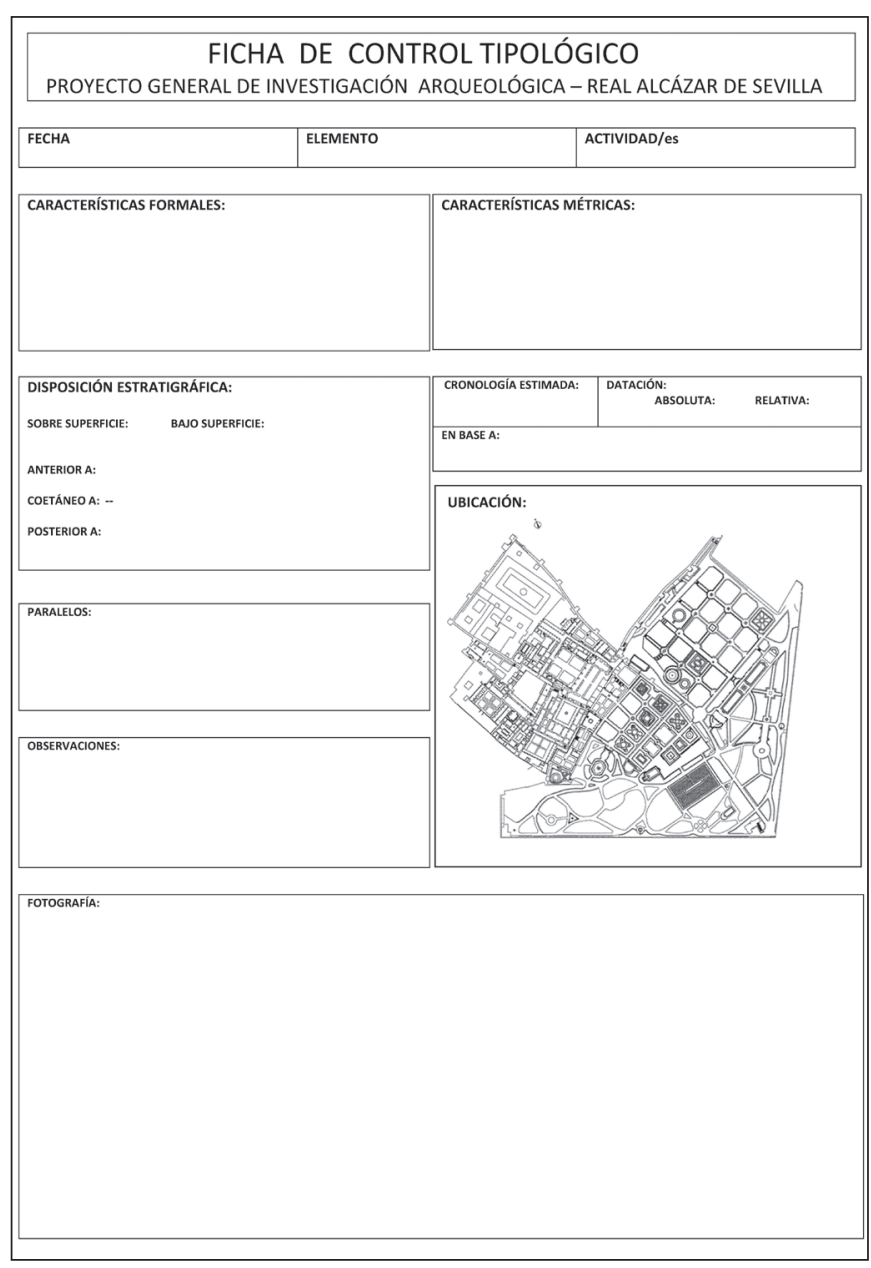

Figura 20. Ficha de registro tipológico empleada para la caracterización de cada técnica constructiva (Tabales, 2002a: 243) variables que intervienen en el proceso productivo de un edificio histórico. La Arqueología de la Arquitectura ya tiene las herramientas, pero hay que optimizarlas a través de un ejercicio de recopilación y ordenación.

\section{REFLEXIONES SOBRE CRONOTIPOLOGÍAS}

Los objetivos expuestos en líneas precedentes pueden resultar demasiado pretenciosos teniendo en cuenta la complejidad de la cuestión que queremos resolver, pues la variedad y diversidad de soluciones constructivas desarrolladas en los diferentes ambientes geográficos hace que este ámbito de estudio sea una especie de rompecabezas que se va resolviendo por partes (es decir, a escala local), pero sin posibilidad de extrapolar a un ámbito territorial más amplio. El mismo Mannoni, precursor de la cronotipología, refiriéndose a la misma declaraba que la consecución de unos cuadros bien definidos suponía una ardua y compleja tarea teniendo en cuenta el método inductivo del que partía su elaboración (Mannoni, 1997: 24). Desde entonces, los especialistas implicados en despejar esta ecuación han hecho todo lo posible por allanar el camino empleando para ello el método científico, utilizando criterios basados en el análisis y la experimentación, o como Sánchez, pasando del lenguaje natural a un sistema cognitivo a través de un sistema descriptivo (Sánchez, 2007:72), pero si lo que pretendemos es poder contestar en un futuro no muy lejano y con unos niveles de certeza elevados las cuatro 


\begin{tabular}{|c|c|c|c|}
\hline Tipo 1 & \multicolumn{3}{|c|}{ Tapial monolitico } \\
\hline Tipo 2 & \multirow{10}{*}{$\begin{array}{l}\text { Tapial } \\
\text { mixto }\end{array}$} & Verdugado en ladrillo & \multirow{2}{*}{ Verdugado } \\
\hline Tipo 3 & & Verdugado en mampuesto & \\
\hline Tipo 4 & & Encadenado en ladrillo & \multirow{2}{*}{ Encadenado } \\
\hline Tipo 5 & & Encadenado en piedra & \\
\hline Tipo 6 & & De fraga encadenado en piedra y verdugado en mampuesto & \multirow{6}{*}{ De fraga } \\
\hline Tipo 7 & & De fraga encadenado en piedra y verdugado en ladrillo & \\
\hline Tipo 8 & & De fraga con témpanos de fábrica mixta & \\
\hline Tipo 9 & & De fraga encadenado y verdugado simple en ladrillo & \\
\hline Tipo 10 & & De fraga encadenado y verdugado doble en ladrillo & \\
\hline Tipo 11 & & De fraga encadenado y verdugado triple en ladrillo & \\
\hline
\end{tabular}

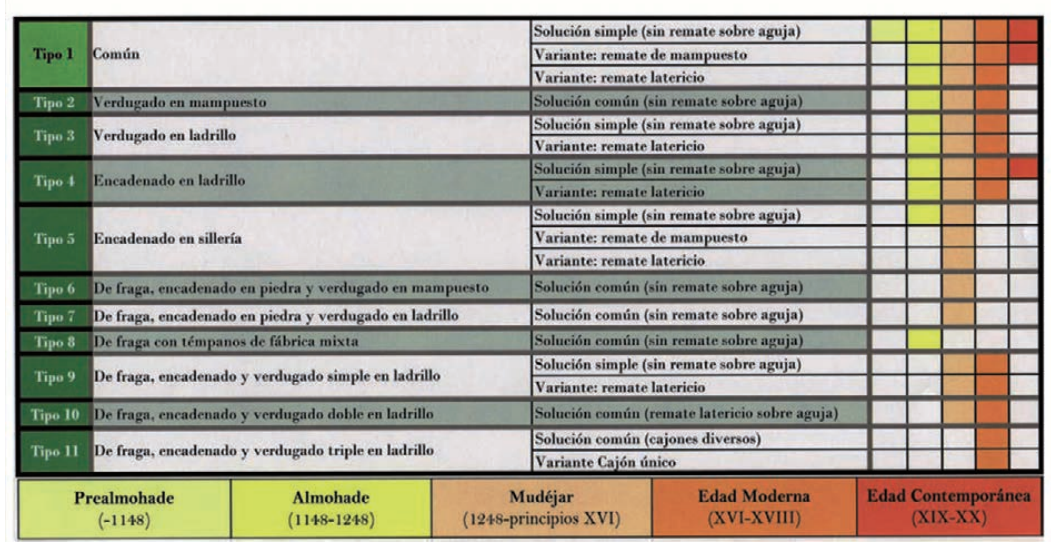

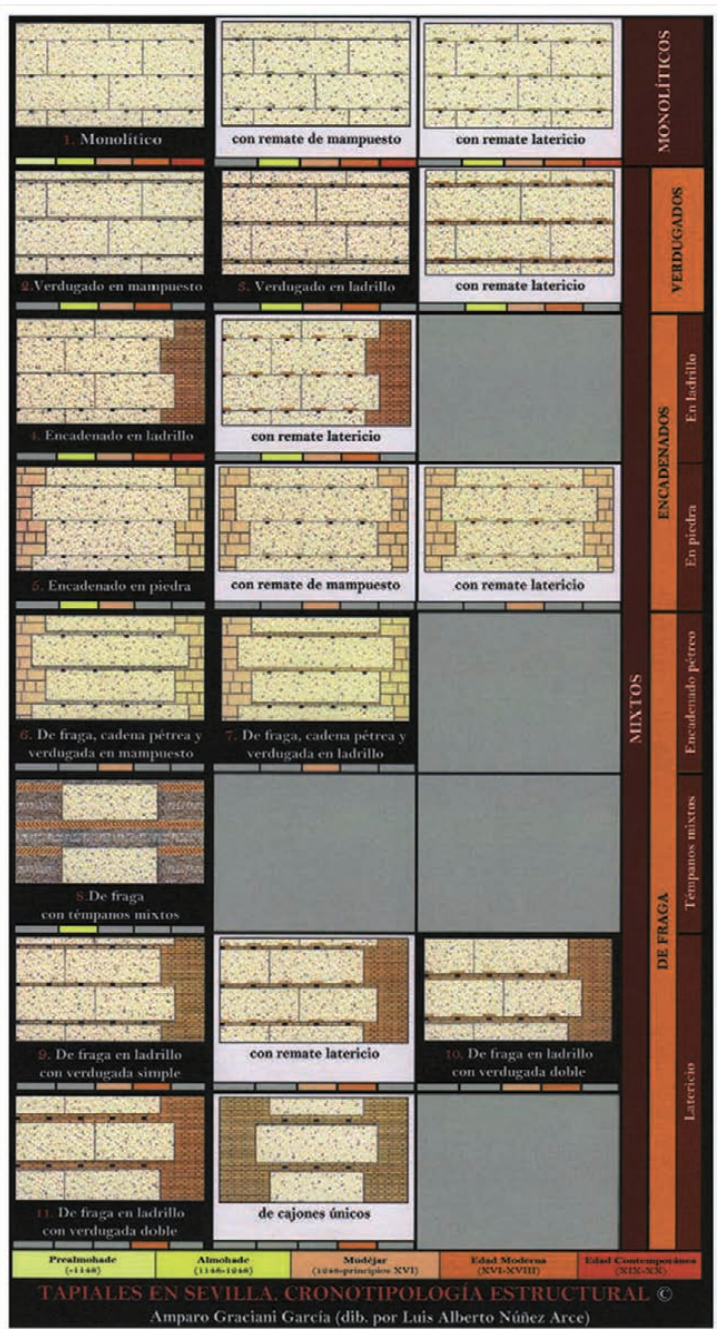

Figura 21. Clasificación tipológica de las fábricas de tapial en Sevilla (Graciani y Tabales, 2008: 138)

preguntas que tan elocuentemente plantea Cressier; a saber, “¿Quién construye?, ¿Para qué se construye?, ¿Con qué se construye?, y sobre todo, ¿Cuándo?” (citado en Caballero, 2009: 143) debemos ser ambiciosos, ya que de no ser así no podremos ir mucho más allá de las comparativas y el establecimiento de paralelos entre cuadros extraídos de estudios específicos. Es cierto que las variables son muchas y variadas, pero esto no significa que no se puedan abarcar en el contexto de un proceso lógico que permita ordenarlas y codificarlas según unos criterios bien definidos. En este sentido, estamos de acuerdo en que cuanto más profundizamos en el análisis de variables implicadas en un proceso productivo más se abre el abanico de posibilidades, pero por otro lado, no tenemos la obligación de tomarlas todas, sino sólo aquellas que tengan un valor lo suficientemente representativo como para ser consideradas como marcadores cronológicos. Por otro lado, no estamos hablando de algo que no se haya hecho ya de manera sistemática ${ }^{19}$ dentro del campo de las ciencias naturales (Sánchez, 2007: 70)

\footnotetext{
${ }^{19}$ Subrayamos en este punto el carácter científico de la Arqueología, pues no dista tanto de la manera de pensar y actuar de las ciencias exactas, la única diferencia existente es su nivel de desarrollo, siendo una muy superior a la otra. Consideramos que este debate está más que resuelto, pero eso no quiere decir que nos olvidemos de ello, si no que debemos seguir reivindicando la arqueometría como parte integrante y esencial del método arqueológico. Muestra de ello es una reflexión llevada a cabo recientemente que parte de la revisión bibliométrica de congresos de arqueometría así como de su presencia en proyectos de investigación de Universidades españolas y publicaciones en revistas y monografías, evaluando su grado de implicación (Martín de la Cruz, 2011: 113-120). Las conclusiones muestran unos resultados carenciales, pues a pesar de la revolución que el empleo de análisis de esta naturaleza supuso para el avance del conocimiento del registro arqueológico, el esfuerzo por emplearlas es aún escaso en términos generales, siendo alarmante la cierta aprensión que sigue existiendo en la actualidad en algunos círculos académicos; según palabras del autor "los investigadores académicos aún no hemos madurado en la percepción de las posibilidades de la Arqueometría" (Martín de la Cruz, 2011: 117).
} 
hace décadas, prueba de ello es el tratado sobre botánica de Linné (1784-1788), o el sistema de clasificación de plantas vasculares que presentaron los botánicos Bonnier y De Layens de la Universidad de la Sorbona en 1897 y que, después de más de un siglo sigue reeditándose y empleándose como libro de cabecera para asignaturas de carreras universitarias de ciencias (Bonnier y De Layens, 1990). A pesar de las diferencias abismales en cuanto a materia objeto de estudio, la problemática que ambas presentan es idéntica, es decir, parten de la intención de clasificar elementos (en su caso plantas vasculares) aparentemente infinitos en cuanto a variables reúnen en sus composición, pero su objetivo no es presentar tablas estáticas en las que éstas aparezcan ya descritas, sino poner a disposición del investigador una serie de claves sinópticas, es decir, un soporte que sirva como guía para que él mismo vaya de manera dinámica y paso por paso caracterizando el elemento hasta llegar a su composición y por tanto a su determinación (en su caso de familias y géneros) a través de un método inductivo. Nuestro caso es aún más complejo ya que, mientras que para las plantas ya están consignados los grupos de familias donde ubicarlas tras su caracterización, nosotros aún no contamos con tipologías homologadas como para hacer lo mismo (precisamente ese es uno de nuestros objetivos) pero por el contrario sí que podemos tomar como válido el mismo procedimiento.

En esta dirección es en la que estamos trabajando actualmente $^{20}$. El objetivo es la ejecución de un modelo interpretativo que tiene como punto de partida el estudio de los materiales y técnicas constructivas de sus murallas, objeto de investigación y análisis por numerosos especialistas $^{21}$. Aunque nuestro estudio se encuentra aún en una fase inicial y experimental, creemos oportuno presentar una primera aproximación que parte de los requerimientos y problemáticas que a escala local ya apuntaba Tabales hace más de una década en su tesis: "disponer de seriaciones que permitan datar con cierto rigor, valorar funcionalmente $y$ definir las pautas locales y regionales". Estos objetivos se han cubierto sólo parcialmente, ya que como comentábamos anteriormente, para el caso de las fábricas en tapial se han

\footnotetext{
${ }^{20}$ Dentro del Proyecto General de Investigación: Análisis arqueológico del Alcázar de Sevilla 2 (2010-2015), dirigido por Miguel Ángel Tabales Rodríguez, financiado por el Patronato del Alcázar y autorizado por la Dirección General de Bienes Culturales de la Junta de Andalucía.

21 Tanto a nivel de investigaciones como de intervenciones arqueológicas: (Valor, 1991; Amores, Rodríguez y Campos, 1987; Campos, Gómez y Carmona, 1993; Tabales y Jiménez, 1998 y diversas publicaciones de Tabales desde el año 1997).
}

hecho sistematizaciones con resultados muy útiles, sin embargo, las fábricas en piedra, ladrillo y mixtas siguen siendo un interrogante aún por resolver. Además, a pesar de contar con clasificaciones, nos encontramos con un problema básico que consiste en la inexistencia de un "lenguaje común” que permita reconocerlas y encuadrarlas en un mismo grupo. En este sentido, agrupando variables iríamos confeccionando una secuencia compuesta por códigos alfanuméricos dando como resultado una tipología concreta, única y encuadrable dentro de un periodo cronológico. La repetición de las experiencias sería las que determinaran cronotipologías, ya que somos conscientes del nivel de desarrollo inicial en el que aún nos encontramos; por ello marcamos como cuestión indispensable el disponer de un soporte único que sirva como referente para codificar de manera homogénea el estudio de las técnicas constructivas históricas. Sólo así podremos llegar a hablar un lenguaje común y sólo hablando un lenguaje común podremos obtener las certezas que precisamos.

Hemos apostado por tanto por iniciar una vía de experimentación a través de la propuesta de unas claves que ayuden a la determinación futura de cronotipologías, siguiendo un esquema homologado y único que se rija inflexiblemente por los principios planteados desde la Arqueología de la Arquitectura. El éxito radica en seguir una estrategia de intervención sobre un fundamento lógico y científico. Partiendo de esta premisa, debemos buscar sistemas que proporcionen certezas, siendo el lenguaje científico el más adecuado, y dentro del mismo, los sistemas cognitivos. Teniendo en cuenta la amplitud de miras que proporcionan (estudio de sistemas inteligentes naturales, artificiales, elaboración de una teoría general a través de la llamada "ciencia cognitiva", etc.), creemos oportuno utilizar la llamada psicología cognitiva, que estudia los sistemas inteligentes del ser humano, y es que si aislamos el elemento producido del productor estaríamos incurriendo en un grave error, descontextualizando la información. Combinando pues condicionantes naturales, humanos y procesos constructivos con las herramientas de la AA, podremos llegar a una comprensión no total, pero sí lo más completa posible del proceso productivo de un edificio (fig. 22). El primer paso fue la elección de un sistema que nos guiara en el proceso; tomamos la psicología cognitiva y, dentro de ella, la metáfora computacional como instrumento auxiliar a la misma para procesar el comportamiento humano. El ser humano, gracias a su capacidad intelectual, puede representar el mundo como 


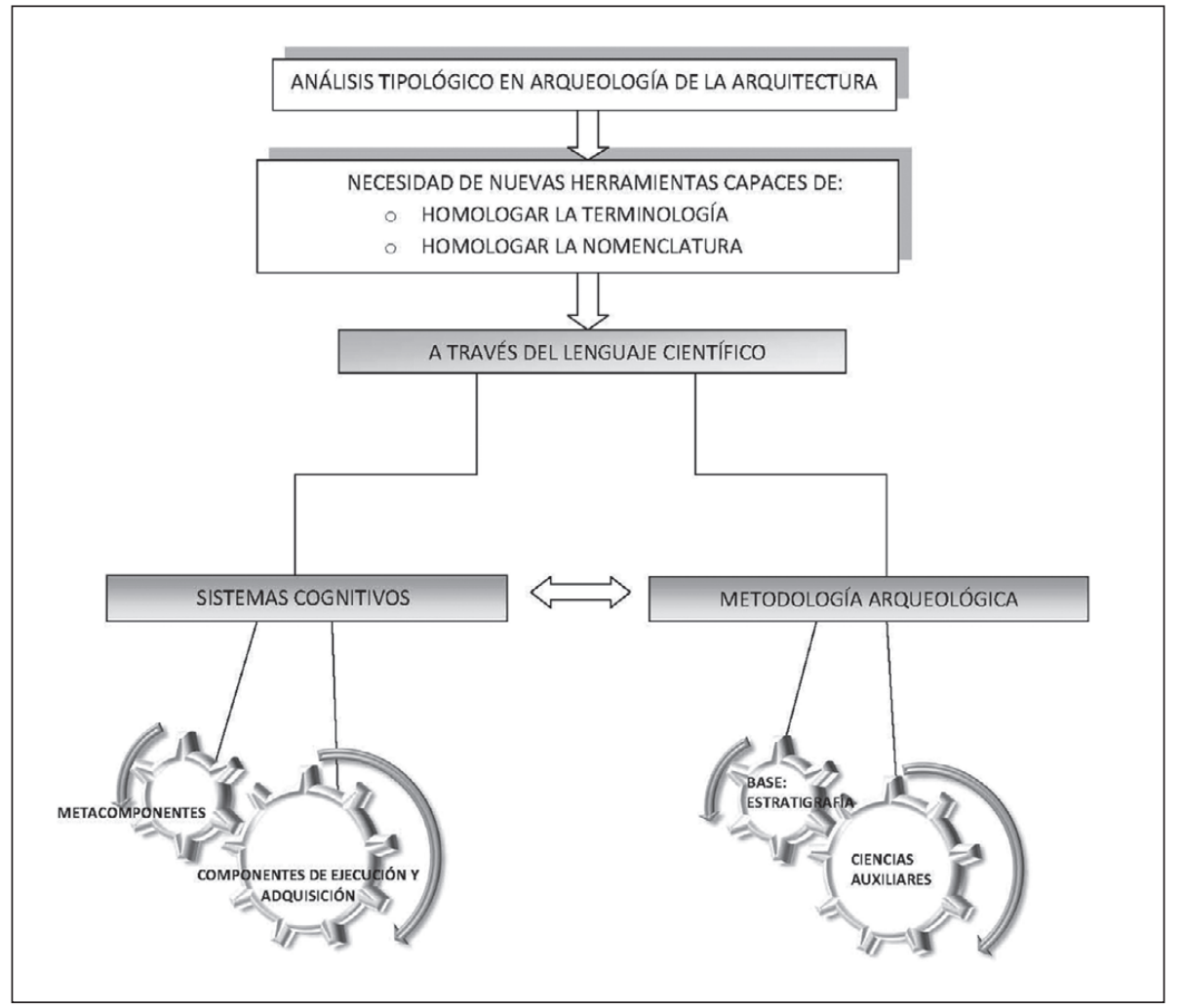

Figura 22. Esquema seguido durante el proceso de trabajo objeto de conocimiento, conceptualizarlo y operar con ese conocimiento, razonando, resolviendo problemas y tomando decisiones, dando lugar a la filosofía, ciencia, arte, tecnología y productos culturales (García, 2007). Pero no solamente debemos tener en cuenta estos condicionantes históricos, culturales y sociales sino también los naturales, siendo susceptibles de tenerse en cuenta en el estudio de cualquier construcción realizada por un grupo humano en el contexto de una localización geográfica determinada.

El siguiente paso, una vez contemplados estos condicionantes previos, fue definir el modelo más idóneo para emprender el estudio del fenómeno constructivo. En nuestra opinión, cuanto más sencillo sea más inferencias podremos extraer, por lo que consideramos que éste no debía ser otro que la inteligencia como estrategia de intervención. Estamos de acuerdo con García en que la conducta inteligente es también una conducta estratégica, mediante la cual podemos resolver problemas siguiendo un procedimiento ordenado. Así pues, a partir de la teoría triárquica de la inteligencia de Sternberg (1982, componencial, exponencial y contextual) resolvimos que podríamos hacer una extrapolación de este modelo analítico y aplicarlo a la resolución de la problemática del proceso constructivo en el contexto del patrimonio edificado. El modelo se basa en los siguientes pasos, mediante la utilización de "metacomponentes” y “componentes de ejecución y adquisición”.

\section{Metacomponentes:}

1. Definición de la problemática a resolver y del procedimiento más adecuado para resolverlo.

2. Selección de aquellas herramientas que van a ser utilizadas para resolver el caso planteado.

3. Selección de la estrategia que resulte más eficaz para combinar las herramientas de análisis.

4. Representar la información de manera clara y eficaz.

5. Localizar los medios y recursos necesarios para resolver el problema.

6. Controlar los procesos y resultados logrados.

Asimismo, los componentes de ejecución y de adquisición están resultando igualmente importantes, pues son estrategias de las que nos valemos para optimizar la información contenida en cada uno de los puntos anteriormente definidos. De esta forma, una vez hecha la toma de datos y posterior ordenación de los mismos con las herramientas descritas, estaríamos en condiciones de extraer conclusiones relativas al descubrimiento de nuevas relaciones y también seríamos capaces de extrapolar inferencias a 
nuevos casos, hacer comparativas, codificaciones y comparaciones selectivas. En definitiva, el modelo consiste en aplicar la inteligencia junto a unos instrumentos analíticos ordenados, sistematizados y coordinados.

Estos planteamientos de partida son los que estamos aplicando para el estudio cronotipológico y de la técnica constructiva de los recintos del Alcázar de Sevilla. Nuestra intención es generar un modelo interpretativo teniendo como soporte una base de datos que codifique las variables constructivas, dando lugar a una sistematización de las mismas a través de una terminología común que sirva para incentivar el empleo de un lenguaje universal que pueda extrapolarse al territorio. En este sentido, estamos de acuerdo con Quirós en que resulta imprescindible que las clasificaciones arquitectónicas partan de microanálisis en zonas con características geográficas e históricas comunes (Quirós, 1994: 147) para que en un segundo momento se pueda verificar la extensión real de cada tipo (Quirós, 1996: 183) Precisamente, esa verificación sería mucho más inteligible si contásemos con unas pautas para establecer una nomenclatura homogénea ${ }^{22}$ que sirviera como instrumento de clasificación funcional, material y tecnológica. Una vez hecha esta operación, estaríamos en circunstancias de hacer discriminaciones entre zonas geográficas, todo ello sin perder de vista la contextualización del edificio dentro de su ambiente productivo, económico y social.

\section{Definición de la problemática a resolver y del procedimiento más adecuado para resolverlo}

Los estudios arqueológicos desarrollados en el Alcázar ${ }^{23}$ han puesto en evidencia la necesidad de mejora del sistema de análisis de las estructuras arquitectónicas en su vertiente constructiva. Esta razón es la que motivó en primera instancia a profundizar en la investigación de las defensas del conjunto palatino aplicando nuevos criterios analíticos que permitieran resolver contradicciones y polémicas abiertas en el contexto de la atribución cronológica, comprensión urbana y la misma justificación histórica. En este sentido, los sistemas defensivos del conjunto son el fruto de la adecuación a las transformaciones urbanas generadas en la ciudad desde el siglo XI al siglo XIV. Cada fase responde a una necesidad defensiva y política diferente siendo el exponente máximo de las técnicas constructivas de cada momento. Dado que en esos siglos

\footnotetext{
22 Este esfuerzo por homogeneizar la terminología ya está presente en trabajos como los de Azkarate (1996 y 2001b) o Sánchez, 2007.

${ }^{23}$ Materializados en el Proyecto General de Investigación denominado “Análisis Arqueológico del Alcázar de Sevilla 2000-2005”.
}

Sevilla es la ciudad más dinámica de la Península y que en el Alcázar se concentra el poder real, primero islámico y después castellano, en toda su expresión simbólica, entendemos que la correcta valoración cronológica y la comprensión de las técnicas empleadas repercutirá en el reajuste de las dataciones y justificación de la arquitectura de esos momentos. Partimos de la hipótesis de que la valoración actual de dichos procesos es errónea desde la base de la adscripción histórica lo que supone por extrapolación una incorrecta valoración por comparación de algunos de los conjuntos palatinos y militares más importantes del Medievo hispano.

\section{Selección de las herramientas que van a ser utilizadas para resolver el caso planteado}

Nuestra pretensión es desarrollar una propuesta de futuras estrategias de intervención relativas al estudio de las técnicas constructivas detectadas en los recintos del Alcázar, estableciendo unos parámetros que permitan generar una cronotipología del conjunto para, en un segundo momento, conocer la extensión a escala regional de cada tipo detectado. Este trabajo se basa en los estudios que llevan realizándose en el conjunto desde el año 1997 atendiendo a investigaciones previas de especialistas en la materia. Asumimos por tanto como válida la herramienta que ha venido empleándose; a saber, la Arqueología de la Arquitectura. En este sentido, además de la lectura estratigráfica del edificio, ya se contaba con una serie de instrumentos (ciencias auxiliares o fuentes directas e indirectas) que han posibilitado la comprensión de los elementos arquitectónicos en su vertiente constructiva. No obstante, estos indicadores no han satisfecho hasta el momento las necesidades que precisamos en el contexto de un edificio pluriestratificado y tipologizado, existiendo en algunos puntos tanto incoherencias en cuanto a adscripciones cronológicas como vacíos de conocimiento relativos a tipologías constructivas. Estas irregularidades son las que pretendemos subsanar con la revisión y renovación de los estudios como las analíticas iniciadas y/o llevadas a cabo con anterioridad, imbricando toda una red de disciplinas científicas implicadas en el ejercicio de la interpretación:

- Actualización y redefinición del sistema de representación gráfica.

- Planimetría ex novo de los tramos de muralla correspondientes a los recintos no estudiados con anterioridad.

- Planimetría actualizada de los recintos ya estudiados. 
Figura 23. Plano estratigráfico de las fases detectadas de la muralla septentrional del Recinto I (Tabales, 2010: 113, 114 )

Figura 24. Plano con las tipologías documentadas utilizando el sistema de lectura de Tabales
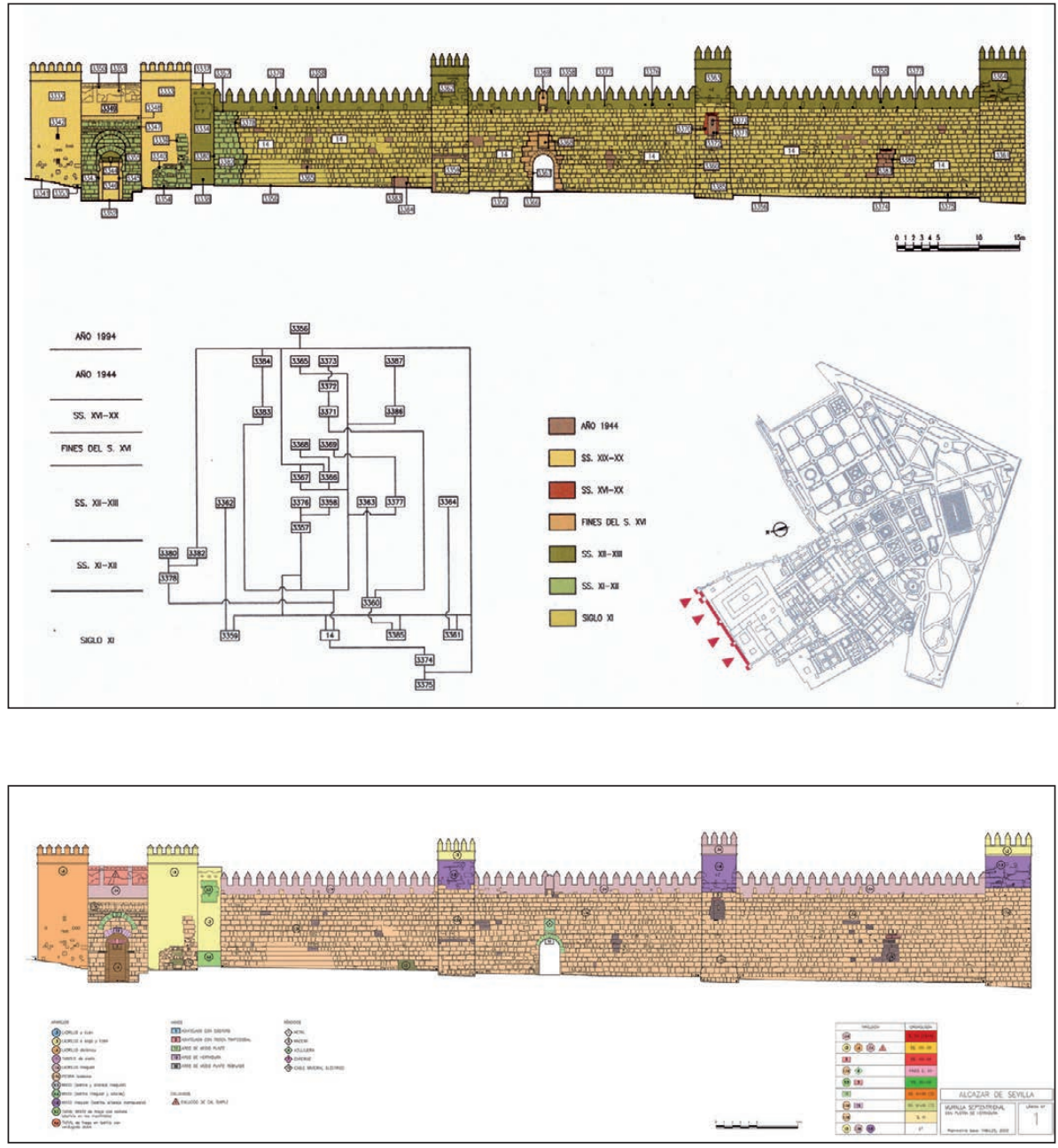

- Relectura de paramentos de los recintos reseñados. Descripción, secuencia, cronología relativa.

- Revisión de las tipologías edilicias detectadas a través del estudio de las fábricas murarias de los recintos.

- Revisión cronológica de las fábricas a fin de establecer cronotipologías fiables.

- Propuesta de nuevos sistemas de recogida de información (Informatización de los datos, fichas y gráficos creados a tales efectos).

- Elaboración de tablas cronotipológicas.

- Sistematización cronotipológica y de la técnica constructiva.

- Incorporación de datos que se desprenden de herramientas de análisis tales como:

- Dataciones radiocarbónicas.

- Mensiocronología.
- Termografía.

- Termoluminiscencia.

- Ciclos productivos.

- Interpretación de resultados obtenidos, poniéndolos en relación con la hipótesis de partida y resultados previos. Planteamiento y resolución de problemas. Nuevas dataciones y propuesta de nuevos modelos interpretativos.

\section{Selección de la estrategia que resulte más eficaz para combinar las herramientas de análisis}

El argumento teórico debe ser lo más dinámico y comprensible posible, es por ello que consideramos que debíamos tender a un discurso fluido en el que todos los datos que se desprendieran de la utilización de las herramientas no se trataran como entes dispersos e individuales sino que se integraran a lo largo de todo el discurso a través de un 


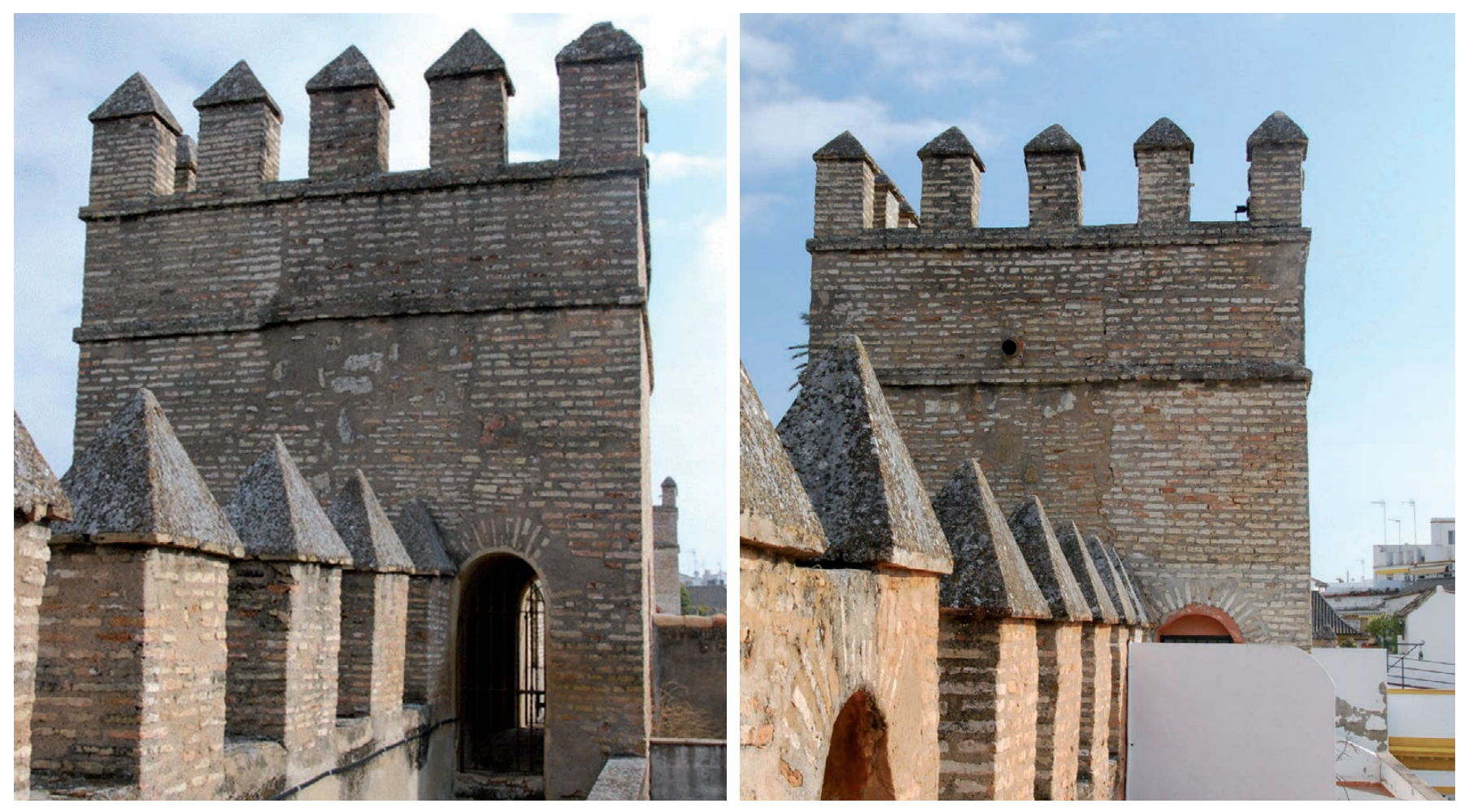

Figuras 25 y 26. Cámaras de las torres centrales del lienzo Septentrional (recinto I, Alcázar de Sevilla) realizadas en aparejo mixto irregular

proceso de retroalimentación en virtud del cual la información obtenida se revisara y actualizara constantemente.

\section{Representar la información de manera clara y eficaz}

Llegados a este punto resulta fundamental poner en marcha el empleo de esas herramientas definidas en el punto número 2 de nuestra estrategia de intervención, estado en el que se enmarca actualmente nuestro análisis.

En este sentido, hemos partido de un trabajo que viene desarrollándose desde 1997, con una "biografía constructiva” generada pero no cerrada y con un alto nivel de complejidad en cuestiones evolutivas. Esta complicación de la que hablamos es especialmente conflictiva pues existen ciertas irregularidades estratigráficas aún no resueltas detectadas durante nuestro proceso de estudios previos $^{24}$ y que irremediablemente imposibilitan en algunos casos elaborar las tipologías que precisamos.

Podemos poner como ejemplos ilustrativos las fábricas mixtas de las cámaras superiores de las torres que coronan las murallas Occidental y Septentrional del Recinto I del Alcázar (figs. 23 y 24), cuya adscripción

${ }^{24}$ Trabajo de investigación denominado "Cronotipologías en Arqueología de la Arquitectura. Estudio de la técnica constructiva en los recintos primitivos del Alcázar de Sevilla”. cronológica está actualmente en proceso de revisión ${ }^{25}$, o el almenado que corona tanto las cámaras de las torres como los tramos de muralla conservada en los recintos primitivos, cuyas fábricas de ladrillo aparejado a soga y tizón han sido objeto de una relectura estratigráfica cuyo resultado plurifásico elimina por completo la tipología asignada inicialmente (figs. 25 y 26).

En definitiva, y considerando el punto en el que se encuentra nuestra investigación, resulta preciso finalizar la revisión estratigráfica para así proceder a la aplicación tipológica. Esta cuestión en la que nos hallamos inmersos actualmente sin embargo no suprime el desarrollo teórico de una herramienta metodológica cuyo fundamento se nutre de las experiencias de casos antes mencionados en combinación con la casuística local, y cuyos resultados

\footnotetext{
${ }^{25}$ El análisis estratigráfico ejecutado por Tabales, 1997, arrojó una primera hipótesis evolutiva que situaba las cámaras dentro de una fase almohade, argumento que cuadraba perfectamente con el discurso tipológico (fábricas mixtas irregulares, realizadas con ladrillo, sillarejo y mampuesto con una cierta tendencia a la horizontalidad, muy frecuentemente empleada en muros de época almohade, Tabales, 2000: 1080). Sin embargo resulta preciso realizar una revisión estratigráfica pormenorizada de sus paramentos, ya que si bien podrían corresponder en origen a una etapa norteafricana, también resulta probable que hubieran sufrido refacciones en momentos posteriores, razonable si tenemos en cuenta los resultados del examen del Carbono 14 practicado en lo que se creía era una fábrica original en la torre de la esquina noroccidental del recinto I, o los resultados, aún inéditos, del análisis arqueológico de la torre occidental de la Puerta del León del Alcázar.
} 
creemos pueden ser muy útiles como base en nuestra búsqueda de una fórmula que resuelva el problema de la organización de las cronotipologías y la denominación de sus variables, cuyo fundamento pasamos a explicar a continuación siguiendo el esquema planteado.

\section{Localizar los medios y recursos necesarios para resolver el problema}

En nuestro caso, el problema no radica en carecer de las herramientas adecuadas o emplearlas incorrectamente, sino en no optimizarlas lo suficiente. En otros ambientes geográficos es posible que las variables que hasta el momento hemos contemplado sirvieran para caracterizar, datar y definir las pautas constructivas, pero lo cierto es que hemos comprobado que siguen existiendo vacíos de conocimiento, máxime cuando estamos ante un panorama constructivo tan rico y variado que exige una revisión de la estrategia de intervención planteada hasta ahora. Es por ello que proponemos no una eliminación o subrogación del sistema empleado, sino una optimización del mismo a través de la incorporación de nuevas herramientas.

En este sentido, a la par que estamos analizando los recintos del Alcázar de Sevilla, hemos ido, conforme a nuestros planteamientos metodológicos, adelantándonos a los futuros problemas de interpretación. La complicación de la que partimos es evidente, y se resume en la incapacidad de hacer en nuestro ámbito clasificaciones con las variables contempladas hasta el momento, por lo que la respuesta resulta igualmente evidente: hemos de diversificar más aún esas variables. La pregunta que esta afirmación suscita puede ser: ¿hasta qué límite? No debemos caer en la obsesión de aplicar un "zoom" a las variables hasta llegar a niveles celulares y por tanto imperceptibles, sino por el contrario tratar de seleccionar las que sean necesarias y suficientes como para crear "variables diagnóstico".

Es por esta razón por la que estamos trabajando en la creación de una base de datos en la que se conjugan tres pilares fundamentales. Los dos primeros son caracterización (a través de la incorporación de un itinerario que sirva como guía para seleccionar nuestras variables) e identificación (con una serie de códigos alfanuméricos siguiendo un procedimiento que dote de nomenclaturas básicas y universales a esas tipologías de partida). En este punto del análisis tendríamos resueltas dos cuestiones: la caracterización (o descripción) y la nomenclatura (o identificación). Estaríamos pues en condiciones de pasar al último punto; el de la determinación. Éste sería el más relevante de los tres, pues valdría para fijar la tipología elaborada como representativa de un periodo cronológico concreto. Para ello nos valdríamos a su vez de dos instrumentos:

- Ciencias auxiliares, a través de analíticas específicas que tomáramos según el caso de estudio (carbono 14, termografía, termoluminiscencia, análisis de documentos, mensiocronología). Sirviéndonos de estas herramientas relacionaríamos, o mejor dicho, interrelacionaríamos la secuencias estratigráficas y sus elementos de datación con las tipologías documentadas, iniciando un proceso de constante retroalimentación que supondría un intercambio permanente de datos. Así, las tipologías irían cargándose de cronologías absolutas, reciclándose periódicamente con nuevos datos fruto de la estratigrafía y analíticas.

- Estadística descriptiva. La base de datos contiene un programa estadístico cuya misión fundamental es registrar la frecuencia con la que se repiten esos mismos códigos (tipologías) y en qué lugares. Estas sencillas operaciones nos resultarán especialmente prácticas para extraer conclusiones con cierto rigor, pues conforme vayamos llenando de experiencias nuestra base de datos a través de los diferentes casos de estudio podremos establecer las pautas de producción, primero, a escala local, y en un futuro, allá donde los condicionantes geográficos, sociales e históricos nos lo permitan.

Para ilustrar mejor nuestra propuesta pondremos una serie de ejemplos prácticos; en este sentido, hemos comentado que el primer paso de nuestro procedimiento sería la caracterización a través de un itinerario-guía de variables contenido en la Base de Datos, ¿cómo?; nuestra intención es que ésta sea lo suficientemente competente como para describir la totalidad de soluciones constructivas sensibles, al menos, a escala local. Para ello debemos hacer un ejercicio de "disección" que pasa por hacer una selección de variables. Como hemos dejado claro, nuestro objetivo no es obsesionarnos haciendo "colecciones" pero sí dar cabida en el sistema de información a todas las que puedan servirnos como indicadores. Es obvio que el ejercicio de ordenación es complejo, pero para ello nos valemos de la estrategia de intervención definida en el punto 3 de metodología: los sistemas inteligentes. Empleando estas pautas de organización iniciaríamos el proceso agrupando las variables dentro de tres grandes racimos o "cluster":
A. Funcionales.
B. Materiales.
C. Técnicas. 


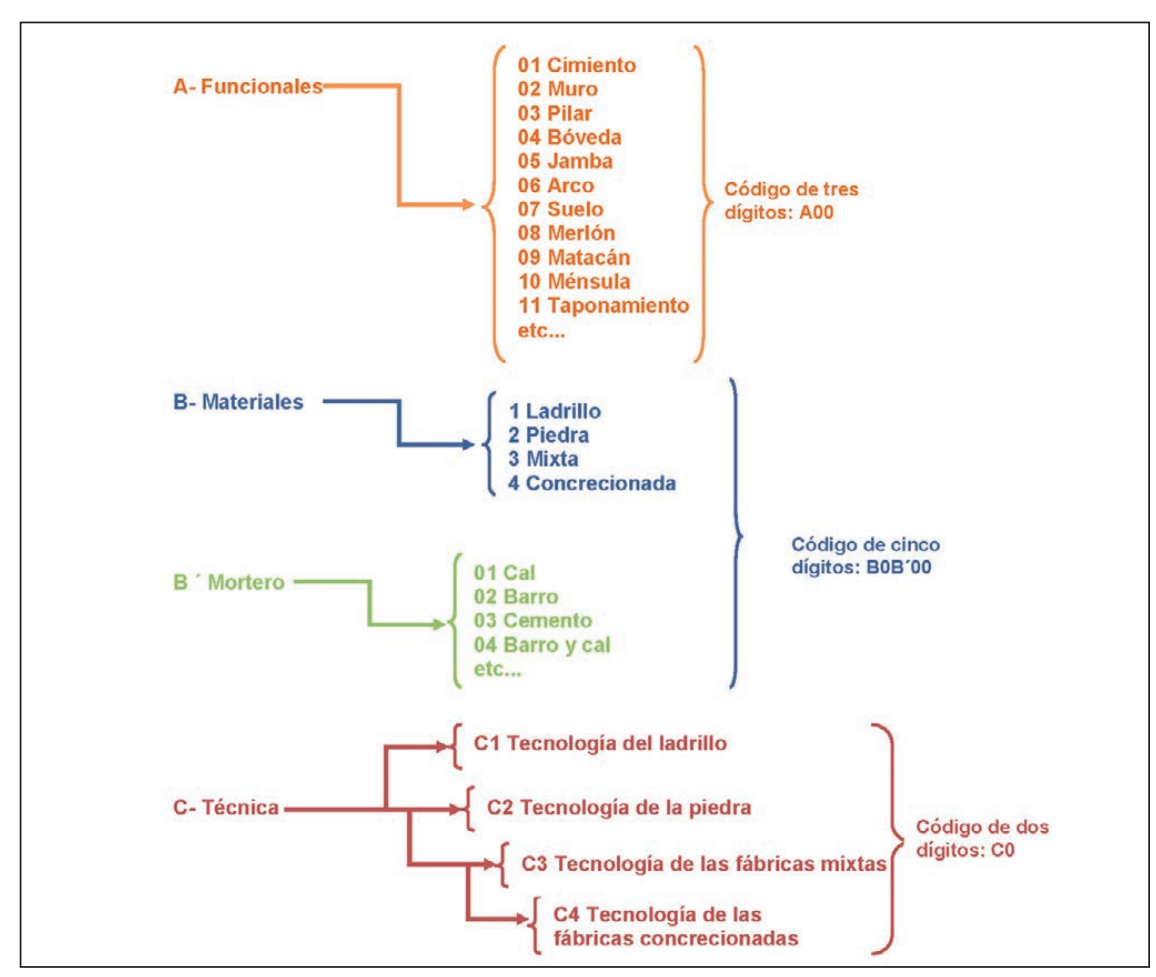

Figura 27. Tabla orientativa de las variables generales con sus códigos asociados
Dentro de cada grupo, irían incluidas todas las recogidas a escala local, siguiendo este esquema y signatura concretos (fig. 27).

Dentro del primer grupo (A) están contenidas indiscriminadamente las variables que responden a una función concreta; esto es, cimiento, muro, pilar, jamba, arco, etc. Cada una de esas variables está asociada a un código numérico de dos dígitos, quedando esta primera parte de la secuencia conformada por una letra y dos números. Esta elección no es caprichosa, sino que tiene una justificación lógica que parte de la idea de crear una signatura única e identificativa, generando "identidades constructivas". Por esta misma razón nuestra elección es matemática; al tratarse de combinaciones de letras y números cuyas posibilidades son infinitas no nos estamos cerrando a la posibilidad de que surjan nuevas soluciones constructivas, sino que por el contrario el propio sistema sería capaz de asumirlas naturalmente ${ }^{26}$. En este sentido, nuestra elección sigue un proceso lógico, seleccionando las letras del alfabeto para los grupos de variables que sabemos que no serán más de 28 (las 28 letras del

\footnotetext{
${ }^{26}$ Se trata de la extrapolación del mismo sistema de registro empleado para otros fines como puede ser la clasificación de sustancias farmacológicas y medicamentos (código ATC, Anatomic, Therapeutic, Chemical classification system), cuyas variables recogen, a saber; el sistema u órgano sobre el que actúa, el efecto farmacológico, las indicaciones terapéuticas y la estructura química del fármaco sobre el que interviene, estructurado en cinco niveles.
}

abecedario) y números para codificar las variables más numerosas, dejando margen a aquellas que puedan documentarse en el contexto de futuras investigaciones. Es el caso de las variables funcionales, cuya codificación está conformada por dos dígitos. En este caso, este grupo sería susceptible de contener 99 variables funcionales, dejando un margen más que amplio para la inclusión de futuras tipologías. Los mismos criterios se han aplicado a las variables restantes. Para el caso de las materiales tendríamos una codificación de cinco dígitos y para las técnicas un código de dos.

Siguiendo este sencillo itinerario tendríamos una primera tipificación muy general compuesta de 10 dígitos, que responderían a una clasificación diferente en cada caso (o igual si estuviera compuesta por las mismas variables. Fig. 28).

El segundo paso sería orientar nuestro foco de atención hacia una de las variables técnicas, discriminando todas las demás. Siguiendo el mismo sistema de codificación empleado hasta ahora, se irían generando tipologías específicas atendiendo a criterios exclusivamente tecnológicos de cada tipo de material (ladrillo, piedra, fábricas mixtas y fábricas concrecionadas).

Cada variable técnica contendría a su vez más variables, (aparejos, herramientas, métrica...), las que fueran necesarias para marcar una pauta cronológica (fig. 29). El resultado sería una signatura dividida en dos bloques: uno 
Figura 28. Ejemplo del itinerario a seguir para la elaboración de codificaciones generales

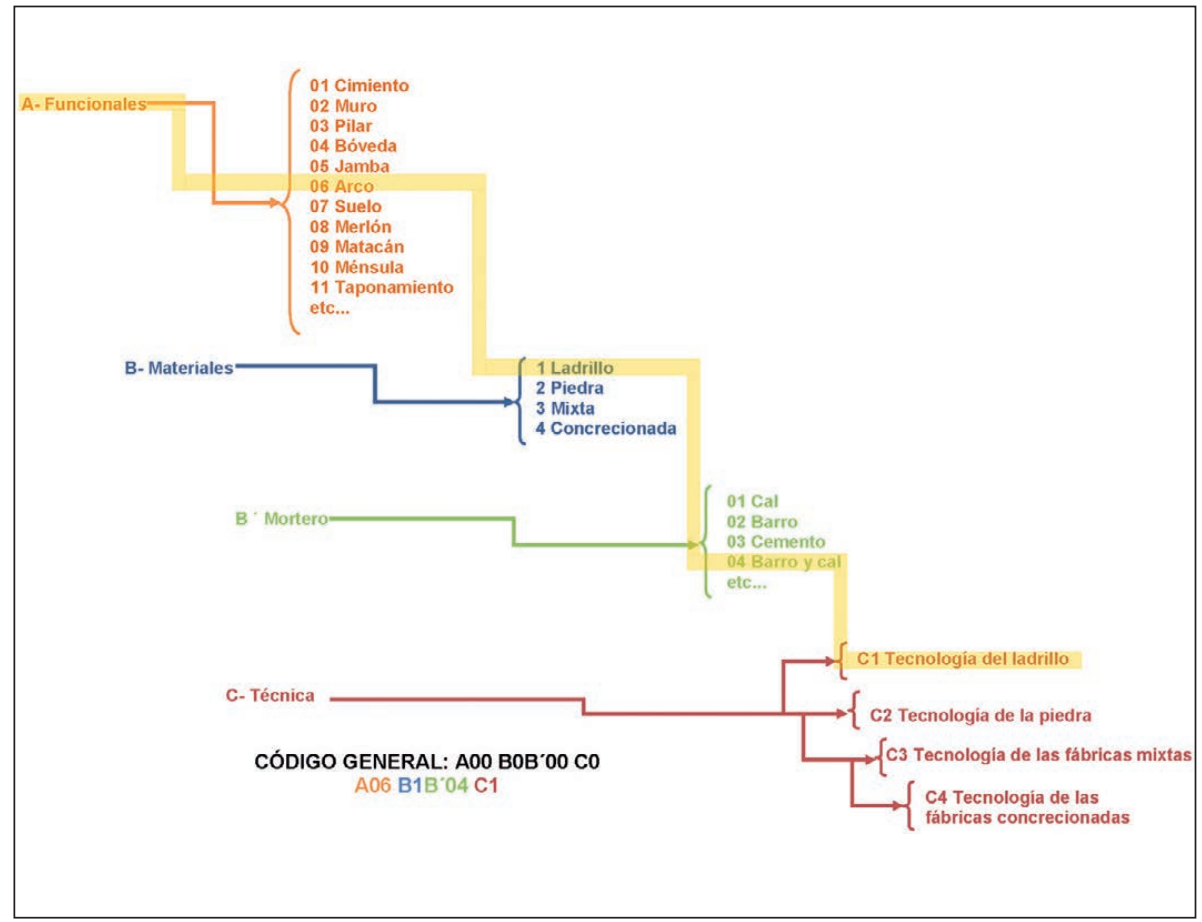

$\{$ C1 Tecnología del ladrillo
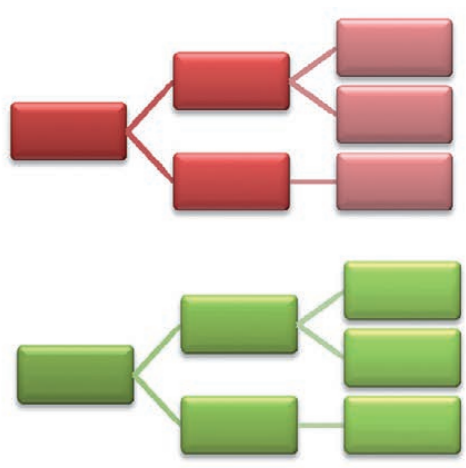

$\{$ C2 Tecnología de la piedra

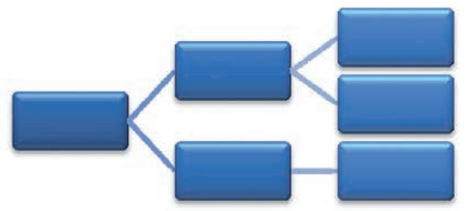

$\{$ C3 Tecnología de las fábricas mixtas

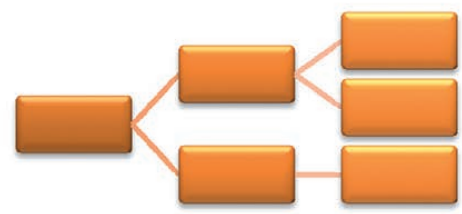

Figura 29. Esquema orientativo

del itinerario a seguir en la elaboración de codificaciones específicas 
general y otro específico como resultado de codificar cada grupo. Ni que decir tiene que la homologación que defendemos no la aplicamos sólo a la creación de signaturas; estaría presente desde el proceso mismo de selección a través del empleo de términos comunes como los ya efectuados para la cerámica (Roselló, 1991). La información en materia constructiva que actualmente los arqueólogos vuelcan en sus informes suele ser deficiente en términos generales, ya que se hace patente la escasez de un vocabulario constructivo que permita analizar el paramento de una manera homogénea en cuanto a términos. Al no haber un conocimiento general sobre construcción, cada especialista hace uso de sus propios recursos lingüísticos en base a sus deducciones. Arquitectos como Pinto Puerto nos hacen este "prurito de rigor" comentando que: "es lógico que, ante el silencio absoluto de las culturas preliterarias, los arqueólogos se vean obligados a describir sus deducciones en términos absolutamente artificiales, o prestados de otras ciencias, adjudicando nombres a lo que van descubriendo, pero en cuanto se mueven en épocas que poseyeron documentos escritos los conceptos tal vez debieran expresarse en palabras coetáneas; por lo tanto es absurdo que, cuando lo que examinan es Arquitectura y ésta se produjo en momentos históricos en que se hablaba castellano, la describan en términos inventados, llegando a unos extremos tales que sus explicaciones son ininteligibles para quienes aún empleamos las palabras originales y con su significado original (...) por ejemplo, un "encastre", traducción directa de un término italiano, es para los nuestros una "jarja” o “adaraja”. Ciertamente los Neandertales murieron sin dejar escritos, pero aún quedan albañiles que saben el léxico de su oficio (Pinto, 2003:113).

Una vez realizada esta operación de caracterización e identificación pasaríamos al tercer y último punto, el de la determinación, consistente en interrelacionar los datos estratigráficos y tipológicos. Para ello debemos partir de una necesaria y exhaustiva comprensión de la realidad evolutiva para de este modo datar las tipologías. Utilizaríamos pues las ciencias auxiliares, agrupándolas en:

- Medios escritos. Consulta de documentación en base a:

- Fuentes documentales.

- Fuentes bibliográficas.

- Fuentes inéditas.

- Medios científicos. Analíticas específicas de materiales (tapiales, morteros, cerámica) con métodos instrumentales determinados, tanto clásicos como novedosos:
- Análisis de materiales en base a dataciones absolutas:

- Termoluminiscencia.

- Radiocarbono.

- Hidroxilación.

- Análisis mineralógicos-texturales mediante la difracción de rayos $\mathrm{X}$, microscopio óptico, petrográfico o de barrido.

- Tests de tenoltaleina para analizar los morteros de cal y sus propiedades físicas (niveles de $\mathrm{PH}$, densidad aparente, real, porosidad accesible al agua).

- Análisis de muestras de tapiales con el objeto de conocer su resistencia a compresión, índices de porosidad, estudios granulométricos para conocer el tipo de áridos (finos-medios-gruesos) que conforman esos tapiales, etc. (fig. 30).

- Mensiocronología como instrumento para la caracterización modular de materiales constructivos,

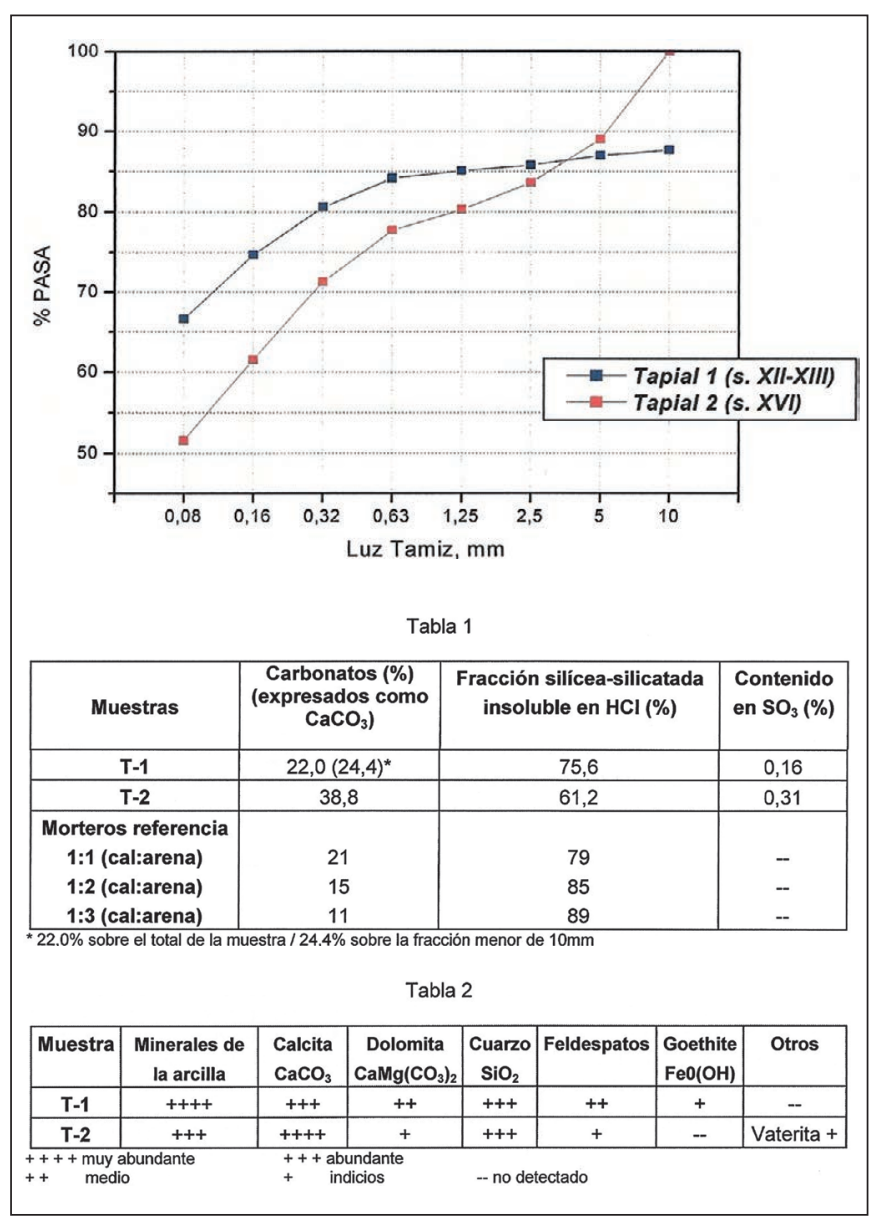

Figura 30. Caracterización de tapiales (análisis de carbonatos, sulfatos y curva granulométrica (Alejandre y Martín del Río, 2003: 16) 
con el objetivo de contextualizar cultural y cronológicamente las estructuras de las que forman parte (Jiménez Hernández, 2009: 130).

\section{Control de procesos, resultados y síntesis final}

En este apartado concluiríamos con la exposición de resultados tras el proceso de análisis combinado con los recursos descritos. En este último punto la base de datos jugaría de nuevo un papel significativo, pues generaría toda una red de información en la que podríamos consultar desde las cuestiones más básicas como la ficha de cada "tipo" detectado, caracterización, definición de las mismas, etc., a las más complejas como detectar su extensión en el tiempo y espacio, entendiendo así su peso específico en el contexto del ciclo productivo tanto del edificio como del ámbito geográfico objeto de estudio.

En este sentido, para ejemplificar de forma sencilla nuestra propuesta, podemos tomar el caso de la fábrica a soga y tizón correspondiente a la merlonatura de la torre noroccidental de la muralla septentrional del Recinto I, cuyas suspicacias en cuanto a cronología hemos evidenciado en páginas precedentes. Hasta ese momento, tan sólo nos valíamos de una variable, la tecnológica, indicando que estábamos ante una fábrica de ladrillos aparejada a soga y tizón tipo I.3 de Tabales. El resto de la caracterización (forma del merlón y sus elementos, tipo de ladrillo, tipo de mortero, etc.) lo teníamos en cuenta como complemento a esa caracterización inicial, pero no como variables susceptibles de convertirse en indicadores cronológicos, de ahí las dudas más que razonables referentes a su datación. Sin embargo, siguiendo nuestro sistema de lectura cronotipológica, tendríamos cubiertas desde el principio, a saber, caracterización e identificación (con metodología exclusivamente arqueológica) y determinación (a través de las ciencias auxiliares).

Para obtener las dos primeras, no tendríamos más que seguir el itinerario planteado generando una tipología concreta de merlón compuesta por un total de trece variables, es decir, una "identidad constructiva". Estaríamos pues ante un merlón (variable funcional cuyo código distintivo es A08), realizado en ladrillo (variable material con código, también único, el B1), con mortero de cal y barro (variable B'04), que responde a la tecnología del ladrillo (variable tecnológica $\mathrm{C} 1$ ) componiendo un código de identificación general de 10 dígitos (A08 B1B'04 C1). Esta primera clasificación es elemental, sin embargo resulta esencial para continuar con la codificación específica. Es aquí donde las variables se complican y ramifican exponencialmente, de ahí que hayamos tenido que agruparlas en función del tipo de tecnología empleada (tecnología del ladrillo, piedra, fábricas mixtas y concrecionadas), ya que de haber intentado concentrar todas las variables técnicas en un mismo bloque el itinerario marcado nos hubiera llevado a callejones sin salida (resultó imposible conjugar y codificar siguiendo una pauta lógica una bóveda de ladrillos, con una concrecionada, o con muro mampostería de tres hojas, por poner algún ejemplo).

Siguiendo con la explicación, para el caso del merlón, incluiríamos, además de las ya mencionadas, tres variables más: la técnica constructiva, el módulo del ladrillo y la forma de la albardilla, generando un código final de 13 dígitos.

Esta clasificación ya nos permite dos cosas: caracterizar de manera exhaustiva y con rigor a la par que sentar las bases para su inmediata definición. En este sentido, las variables específicas ya nos estarían marcando diferencias muy claras con respecto a otros tipos de merlón, poniendo de manifiesto su identidad como una tipología concreta en el contexto de una etapa determinada.

Lo siguiente sería el paso de "lo relativo" a "lo absoluto" a través de las ciencias auxiliares, analizando con arqueometría, o con las técnicas de las que dispongamos, las fábricas objeto de estudio.

El merlón estaba datado con Carbono 14, arrojando una cronología moderna (1788 \pm 35$)$, encajando a la perfección con los argumentos arqueológicos, ¿Estaríamos pues en condiciones de presentar este tipo de merlón como un cronotipo?, es decir, ¿encuadrable en un momento histórico concreto debido a sus variables funcionales, materiales, técnicas y formales? Por lo pronto, los niveles de certeza serían muy elevados, pero además aquí es donde de nuevo la codificación toma protagonismo, pues al haber generado un código único en nuestra base de datos, podríamos conocer la extensión de ese tipo (comprobando simplemente si el código se repite, no se repite, si lo hace parcialmente (con lo cual estaríamos ante una variante del mismo tipo), etc., abriéndonos un mundo de relaciones e inferencias, siendo las experiencias en otras zonas el motor que guiara la futura determinación de esa tipología.

\section{CONCLUSIONES}

Resulta indiscutible la complejidad conceptual que encierra la palabra "tipo” en según qué disciplinas, siendo la Arqueología de la Arquitectura la impulsora de su 
salto cualitativo al imprimirle un carácter científico y potencialmente "datante" que no poseía en otros ámbitos de conocimiento. Sin embargo, a raíz de nuestra revisión hemos hallado ciertos desajustes que parten de la imposibilidad, hasta el momento, de encontrar una pauta susceptible de conjugar y relacionar fácilmente tipologías, exceptuando ámbitos geográficos reducidos. Dicho desajuste no implica en ningún caso que la metodología empleada hasta ahora sea errática; por el contrario, la carencia que detectamos tiene que ver con la necesidad de homologar terminologías y nomenclaturas, o dicho de otro modo, establecer un referente que nos permita llamar a las cosas por su nombre, aquí y en cualquier otro lugar. El estadio en el que ahora nos encontramos resulta muy inicial, y la complicación es alta debido a las dificultades de homologación dadas las implicaciones geográficas, técnicas, materiales y humanas. No obstante, el potencial instrumental que ofrece la Arqueología de la Arquitectura supera con mucho los escollos que podamos encontrar en el camino. ¿Cuál sería por tanto nuestra aportación? Incluir dentro del actual sistema de lectura cronotipológica una herramienta que conjugue las variables seleccionadas conforme a un lenguaje matemático generando códigos, de manera que no haya solapamiento de tipos o confusión a la hora de referimos a una técnica constructiva determinada. Con esto habríamos logrado marcar las pautas en cuanto a la caracterización, una cuestión de por sí importante si consideramos el escaso manejo de vocabulario constructivo que en general se detecta en los arqueólogos así como la divergencia en cuanto a consenso de terminologías que hace que la misma cosa reciba nombres diferentes, algunos inventados en el peor de los casos. Pero esto es sólo el comienzo. Nuestro objetivo es que esas codificaciones se conviertan, en un futuro no muy lejano, en técnicas constructivas con nombres y apellidos, totalmente definidas a través de sus variables, encuadrables dentro de una tipología concreta, en una fase cronológica determinada y contextualizada en su ámbito geográfico y productivo. Esto sólo se podrá conseguir a través de la inclusión en la base de datos de experiencias en otros lugares que permitan saber la extensión efectiva de cada tipo (cada código) y la cadencia con la que se produce. Esperamos por tanto que el caso práctico en el que actualmente estamos aplicando el sistema propuesto sirva de motor impulsor para generar el modelo interpretativo que precisamos, contribuyendo a una mejora en la calidad y cientificidad de los análisis tipológicos en Arqueología de la Arquitectura.

\section{Agradecimientos/Acknoledgements}

Proyecto General de Investigación “Análisis Arqueológico del Alcázar de Sevilla”, dirigido por el Dr. Miguel Ángel Tabales Rodríguez.

\section{Bibliografía}

Adam, J. P. 1996: La construcción romana: materiales y técnicas. Editorial de los Oficios. León.

Amores Carredano, F., Rodríguez J. M. y Campos, J. M. 1987: “Excavaciones en las murallas medievales de Sevilla, sector coracha Torre del Oro”, en Anuario Arqueológico de Andalucía 1985, pp. 343-345. Junta de Andalucía. Consejería de Cultura.

Arce Sainz, F. 2009: "Historia del Arte, Arqueología de la Arquitectura y el telescopio de Galileo”, Arqueología de la Arquitectura, 6, pp. 21-29, [en línea] http://dx.doi.org/10.3989/arqarqt.2009.09002.

Azkarate Garai-Olaun, A. 1996: "Algunos ejemplos de análisis estratigráficos en la arquitectura del País Vasco", en Caballero, L. y Escribano, C. (eds.), Arqueología de la Arquitectura. El método arqueológico aplicado al proceso de estudio e intervención en edificios históricos, pp. 123-139. Junta de Castilla y León, Salamanca.

Azkarate Garai-Olaun, A. 2001a: Arqueología de la Arquitectura. Experiencias de investigación desde la Universidad del País Vasco. Lección inaugural de apertura del Curso Académico 2001-2002. Bilbao, [en línea], https://www. academia.edu/1267257/AZKARATE_A._2001_Arqueologia_de_la_Arquitectura_Experiencias_de_investigacion_desde_la_Universidad_de-_Pais Vasco_Leccion_inaugural_de_apertura_del_Curso_Academico_de_la_Universidad del Pais Vasco Euskal Herria

Azkarate Garai-Olaun, A. 2001b: "Catedral de Santa María (VitoriaGasteiz)”, Arkeoikuska: Investigación arqueológica, 2000, pp. 156-165. Gobierno Vasco. Centro de Patrimonio Cultural Vasco. País Vasco.

Bendala Galán, M. 1992: "Materiales de Construcción romano: peculiaridades en Hispania”, en Rodá I., Ciencias, metodologías y técnicas aplicadas a la arqueología, pp. 215-226. Fundación la Caixa y Universidad Autónoma de Barcelona. Barcelona.

Bendala Galán, M. y Roldán Gómez, L. 1999: "El cambio tecnológico en la arquitectura hispanorromana: perduración, novedades y peculiaridades”, II Congreso de Arqueología Peninsular, vol. IV, Arqueología romana y medieval, pp.103-115. Madrid.

Bianchi, G. 2005: "Tecniche costruttive e strutture di potere nella Toscana sud-occidentale (secc. VIII-XIV)", Arqueología de la Arquitectura, 4, pp. 47-59.

Bonnier, G. y De Layens, G. 1990: Claves para la determinación de plantas vasculares. Omega, Barcelona.

Caballero Zoreda, L y Latorre Macarrón, J. I. 1980: La Iglesia y el monasterio visigodos de Santa María de Melque (Toledo). Arqueología y arquitectura. San Pedro de Mata y Santa Comba de Bande. Serie Excavaciones Arqueológicas en España, 109. Ministerio de Cultura. Madrid.

Caballero Zoreda, L. 1995: "Método para el análisis estratigráfico de construcciones históricas o lectura de paramentos”, Informes de la Construcción, 435, pp. 37- 46. [en línea] http://dx.doi.org/10.3989/ic.1995.v46.i435.1096

Caballero Zoreda, L. y Arce Sainz, F. 1997: "La iglesia de San Pedro de la Nave (Zamora). Arqueología y arquitectura", Archivo Español de Arqueología, 70, pp. 221-274.

Caballero Zoreda, L. 2000: "Paleocristiano y Prerrománico. Continuidad e innovación en la arquitectura cristiana hispánica”, en Santos, J. y Teja R. (eds.), El Cristianismo. Aspectos históricos de su origen y difusión en Hispania. Anejos de Veleia, vol. 4, pp. 91-132.

Caballero Zoreda, L. 2009: "Reflexiones a partir del estudio de aparejos constructivos altomedievales", en Suárez, Á. (coord.), Construir en al Andalus, Monografías del Conjunto Monumental de la Alcazaba, 2, pp.143-161. Consejería de Cultura. Sevilla.

Cagnana, A. 2005: "L'introduzione dell'opera quadrata medievale a Génova: aspetti tecnologici e contesto sociale”, Arqueología de la Arquitectura, 4, pp. 23-45. 
Campos, J. M., Gómez, A. y Carmona, P. 1993: "Investigaciones históricoarqueológicas en el recinto de la antigua Casa de la Moneda de Sevilla”, en Anuario Arqueológico de Andalucía 1991, pp. 421-429. Junta de Andalucía. Sevilla.

Clairac y Saénz, P. 1877: Diccionario general de arquitectura e ingeniería. Madrid.

Cómez Ramos, R. 1996: El Alcázar del Rey don Pedro. Diputación Provincial de Sevilla. Sevilla.

Ferrando, I., Mannoni, T. y Pagella, R. 1989: "Cronotipología”, Archeologia Medievale, XVI, pp. 647-661.

Gabrielli, F. 1996: "La Cronotipología relativa come metodo di analisis degli elevati: la facciata del Palazzo Pubblico de Siena”, Archeologia dell’ architettura, 1, pp.17-40.

García García, E. 2007: "Primera ponencia, Teoría de la mente y Ciencias Cognoscitivas”, en Feito, L. (ed.), Nuevas perspectivas cientificas y filosóficas sobre el ser humano, pp. 17-54. Universidad Pontificia de Comillas. Madrid.

Graciani García, A. y Tabales Rodríguez, M. Á. 2008: "El tapial en el área sevillana. Avance cronotipológico estructural”, Arqueología de la Arquitectura, 5, pp. 135-158.

Graciani García, A. 2009: "La técnica del tapial en Andalucía Occidental", en Suárez, Á. (coord.), Almería, puerta del Mediterráneo (ss. X-XIII), pp.111141. Monografías del Conjunto Monumental de la Alcazaba, 2, Consejería de Cultura. Sevilla.

Jiménez Martín, A. 1989: La puerta de Sevilla en Carmona, Consejería de Obras Públicas y Transportes, Sevilla.

Linné, Carl von 1784-1788: Parte práctica de botánica del Caballero Carlos Linneo, que comprende las clases, órdenes, géneros, especies y variedades de plantas, con sus caracteres genéricos y específicos, sinónimos más selectos, nombres triviales, lugares donde nacen y propiedades. Traducida del latín en castellano e ilustrada por Antonio Palau y Verderá, imprenta real, Madrid.

Lugli, G. 1957: La técnica edilizia romana. Bardi. Roma.

Mannoni, T. 1976: "L'analisi delle tecniche murarie medievali in Liguria", en, Atti del Colloquio internazionale di archeologia medievale, pp. 291300. Istituto di Storia Medievale, Università di Palermo. Palermo.

Mannoni, T. 1994a: "Metodi di datazione dell'edilizia storica", Archeologia Medievale, XI, pp.396-401.

Mannoni, T 1994b: Archeologia delle tecniche produttive. Venticinque anni di archeologia globale. ESCUM. Génova.

Mannoni, T. 1997: "Il problema complesso delle murature storiche in pietra I. Cultura material e cronotipologia”, Archeologia dell'architettura, 2, pp. 15-24.

Martín de la Cruz, J. C. 2011: "Arqueometría: Su futuro en Andalucía”, en Memorial Luis Siret. I Congreso de prehistoria de Andalucía. La tutela del patrimonio prehistórico, pp. 113-120. Junta de Andalucía, Consejería de Cultura. Sevilla.

Miyares Fernández, A. 1986: "Tipología de paramentos en el románico asturiano. Método de datación arqueológico-artístico”, en Actas del I Congreso de Arqueología Medieval Española, vol. I, pp.425-436. Diputación General de Aragón. Zaragoza.

Parenti, R. 1983: "Le strutture murarie: problemi di metodo e prospettive di ricerca, Relazione preliminare,1982", Archeologia Medievale, 10, pp. 332-338

Parenti, R. 1988: "Sulle possibilità di datazione e classificazione delle murature, en Francovich, R. y Parenti, R., Archeologia e restauro dei monumenti, pp. 280-304. Università di Siena. Firenze.

Pavón Maldonado, B. 1999: Tratado de Arquitectura Hispano-Musulmana II, ciudades y fortalezas. Consejo Superior de Investigaciones Científicas. Madrid.

Pinto Puerto, F. 2003: Levantamiento y análisis de edificios. Tradición y futuro. Universidad de Sevilla, Instituto Universitario de Ciencias de la Construcción. Sevilla.

Pizzo, A. 2009: "La Arqueología de la construcción. Un laboratorio para el análisis de la arquitectura de época romana”, Arqueología de la Arquitectura, 6, pp. 31-45. [en línea] http://dx.doi.org/10.3989/arqarqt.2009.09001.

Plata Montero, A. 2003: "La aplicación de la arqueología de la arquitectura a un complejo productivo. El valle salado de las Salinas de Añana (Álava)", Arqueología de la Arquitectura, 2, pp. 241-248.
Plata Montero, A. 2008: Génesis de una villa medieval. Arqueología, paisaje $y$ arquitectura del valle salado de Añana (Álava). Universidad del País Vasco. Facultad de Filología e Historia. Vitoria-Gasteiz.

Quirós Castillo, J. A. 1992: "Cronotipología di portali nell'alta Valdinievole: la montagna Pesciatina”. Archeologia Medievale, 19, pp.729-739.

Quirós Castillo, J. A. 1994: "Contribución al estudio de la arqueología de la arquitectura”. Arqueología y territorio medieval, 1, pp. 141-158. Universidad de Jaén: Área de Historia Medieval. Jaén.

Quirós Castillo, J. A. 1996: "Indicadores cronológicos de ámbito local: cronotipología y mensiocronología”, en Caballero, L. y Escribano, C. (eds.), Arqueología de la Arquitectura. El método arqueológico aplicado al proceso de estudio e intervención en edificios históricos, pp. 179-187. Junta de Castilla y León, Salamanca.

Quirós Castillo, J. A., Fernández Mier, M., 2001: "La evolución de las técnicas constructivas en Asturias en la Edad Media”, en Actas del V Congreso de Arqueología Medieval EspañolaI, vol. I, pp. 371-382. Junta de Castilla y León. Valladolid.

Quirós Castillo, J. A. 2002: Modi di costruire a Lucca nell'altomedievo. Biblioteca del Dipartimento di Archeologia e Storia dell'Arti dell'Università di Siena, 4. Florencia.

Quirós Castillo, J. A. 2005a: “¿Por qué un monográfico sobre las técnicas constructivas?”, Arqueología de la Arquitectura, 4, pp. 7-9.

Quirós Castillo, J. A. 2005b: "Técnicas constructivas altomedievales en la ciudad de Pisa y en la Toscana nordoccidental”, Arqueología de la Arquitectura, 4, pp. 81-109.

Rodríguez Gutiérrez, O. 2004: El teatro romano de Itálica: estudio arqueoarquitectónico. Universidad Autónoma de Madrid. Madrid.

Roldán Gómez. L. 1992: Técnicas constructivas romanas en Carteia (San Roque, Cádiz), en Monografías de Arquitectura romana, 1. Universidad Autónoma de Madrid. Madrid.

Roselló Bordoy, G. 1991: El nombre de las cosas en Al-Andalus: una propuesta de terminología cerámica. Museo de Mallorca. Societat Arqueològica Lul-liana. Palma de Mallorca.

Sánchez Zufiaurre, L. 2007: Técnicas constructivas medievales: nuevos documentos arqueológicos para el estudio de la alta Edad Media en Álava. Gobierno Vasco. Vitoria-Gasteiz.

Sternberg, R. J. 1987: Inteligencia humana, 4 vols. Paidós, Barcelona.

Tabales Rodríguez, M. Á. 1997: “La arqueología en edificios históricos. Propuesta de intervención y análisis global a través de la experiencia sevillana”. PH. Boletín del Instituto Andaluz del Patrimonio Histórico, vol. 5, Núm. 20, pp. 65-81. Instituto Andaluz del Patrimonio Histórico. Consejería de Cultura. Junta de Andalucía.

Tabales Rodríguez, M. Á. 2000: “Algunas reflexiones sobre fábricas y cimentaciones sevillanas en el período islámico”, en Graciani, A. et al., Actas del III Congreso Nacional de Historia de la Construcción, vol. II, pp. $1077-$ 1088. Universidad de Sevilla, Sevilla.

Tabales Rodríguez, M. Á. 2002a: Sistema de Análisis Arqueológico de Edificios Históricos. Universidad de Sevilla, Instituto Universitario de Ciencias de la Construcción. Sevilla.

Tabales Rodríguez, M. Á. 2002b: La primitiva puerta del Alcázar de Sevilla: memoria arqueológica. Parques Nacionales. Madrid.

Tabales Rodríguez, M. Á., Pozo Blázquez, F. y Oliva Alonso, D. 2002: Análisis arqueológico: el cuartel del Carmen de Sevilla, Junta de Andalucía, Consejería de Cultura. Sevilla

Tabales Rodríguez, M. Á. 2010: El Alcázar de Sevilla. Reflexiones sobre su origen y transformación durante la Edad Media. Memoria de Investigación Arqueológica, 2000-2005. Junta de Andalucía, Consejería de Cultura.

Valor Piechotta, M. 1991: La arquitectura militar y palatina en la Sevilla musulmana. Diputación provincial de Sevilla. Sevilla.

\section{Memorias cientificas inéditas consultadas}

Alejandre Sánchez, J. y Martín del Río, J. J. 2003: "Estudio de paramentos en el Monasterio de Santa Clara”, en Tabales Rodríguez, M. Á., Real Monasterio de Santa Clara. $1^{a}$ fase de estudios arqueológicos, tomo III (informe inédito). 
Jiménez Hernández, A. 2009: "Informe mensiocronológico del Alcázar de Sevilla”, en Tabales Rodríguez, M. Á., Informe preliminar Intervención Arqueológica puntual. Patio de Banderas del Alcázar de Sevilla (informe inédito).

Tabales Rodríguez, M. Á. 1995: Estudio arqueológico del Palacio Conde de Ibarra 18 (memoria inédita).
Tabales Rodríguez, M. Á. y Jiménez Sancho, A. 1998: Memoria Cientifica de la Intervención Arqueológica en el Pabellón de Oficinas de la Catedral de Sevilla (memoria inédita).

Tabales Rodríguez, M. Á. 2001: Proyecto general de investigación: Análisis arqueológico del Real Alcázar de Sevilla, año 2001, sondeos estratigráficos, II (SE/VI-SE/IX) (memoria inédita). 